$18 / 91197$ DOE/FE-0363

\title{
Sustainable Development With Clean Coal
}

\section{RECEWED SER 12 M OSTI}

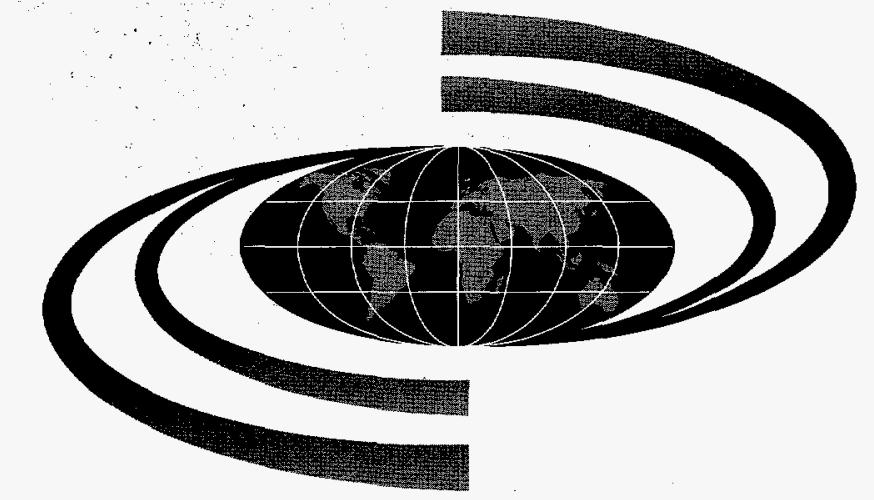

U.S. Department of Energy

OfFice of Fossil ENERGy

Office of CoAl \& Power Import and Export August 1997 


\section{DISCLAIMER}

This report was prepared as an account of work sponsored by an agency of the United States Government. Neither the United States Government nor any agency thereof, nor any of their employees, makes any warranty, express or implied, or assumes any legal liability or responsibility for the accuracy, completeness, or usefulness of any information, apparatus, proctuct, or process disclosed, or represents that its use would not infringe privately owned rights. Reference herein to any specific commercial product, process, or service by trade name, trademark, manufacturer, or otherwise does not necessarily constiute or imply its endorsement, recommendation, or favoring by the United States Government or any agency thereof. The views and opinions of authors expressed herein do not necessarily state or reflect those of the United States Government or any agency thereof.

This report has been reproduced directly from the best available copy.

Available to DOE and DOE Contractors from the Office of Scientific and Technical Information, P.O. Box 62, Oak Ridge, TN 37831; prices available from (423) 576-8401.

Available to the public from the U.S. Department of Commerce, Technology Administration, National Technical Information Service, Springfield, VA 22161, (703) $487-4650$. 


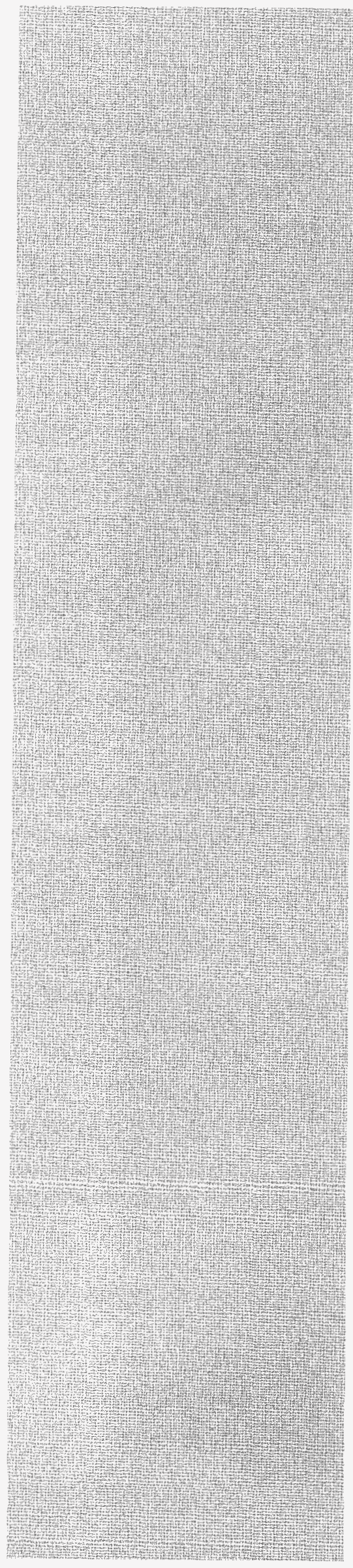

\section{Sustainable Development With Clean Coal}

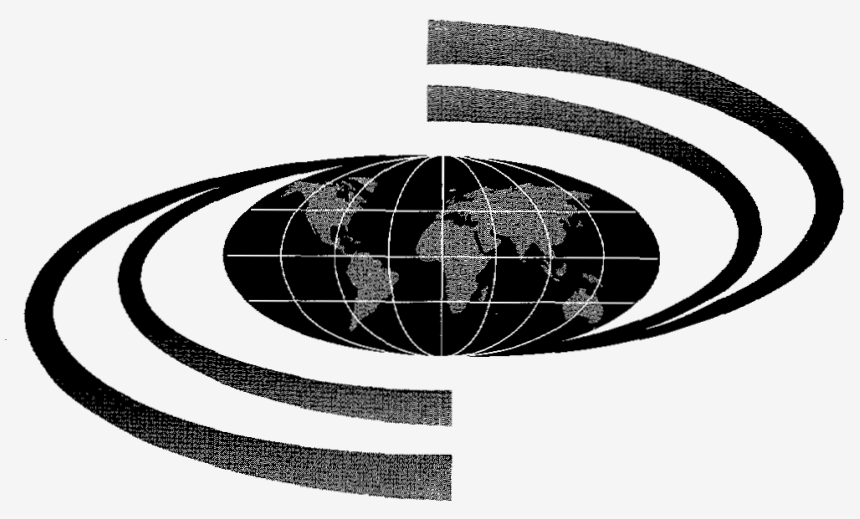

U.S. Department of Energy

Office of Fossil ENERgy

Office of Coal \& Power Iyport and Export

DISTRIBUTION OF THIS DOCUMENT IS UNLIMITED

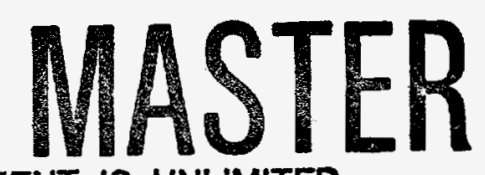



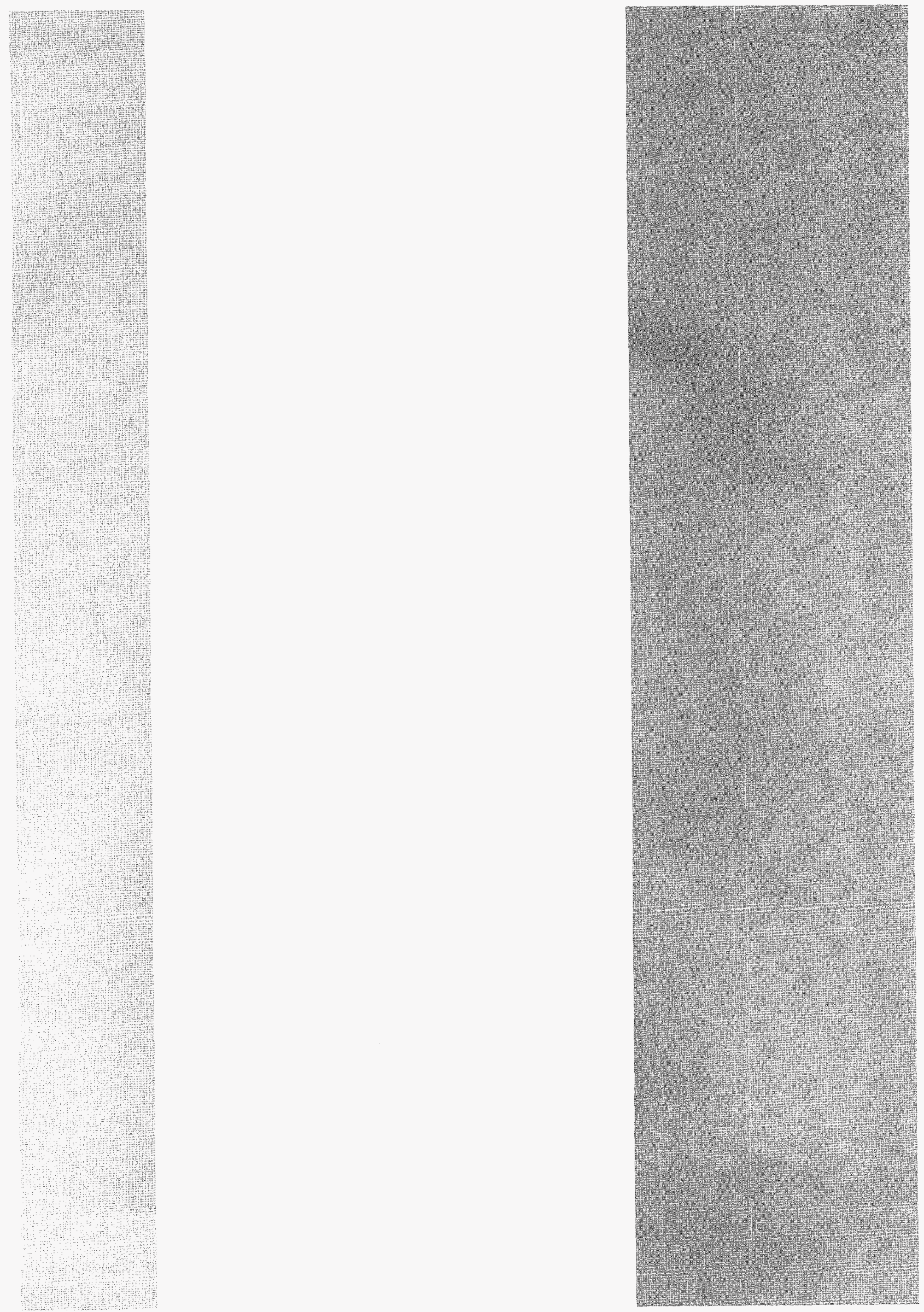


\section{Contents}

Sustainable Development with Clean Coal ............................. 1

Clean Coal Technologies - An Opportunity For Today ..... 3

The Benefits Are ReAL ....................................................... 7

Clean Coal Technologies For New Power Plants .................. 9

Clean Coal Technologies For Existing Power Plants ........ 11

RETROFIT OPTIONS ………………….............................. 11

REPOWERING OptIONS .......................................................... 12

Industrial, Commercial, And Domestic ApPlications ............ 13

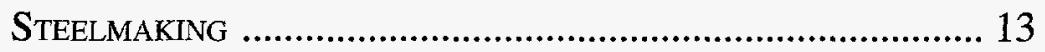

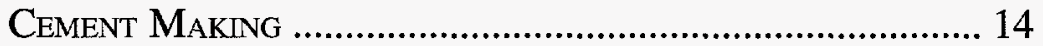

PULP AND PAPER MANUfACTURING ......................................... 14

Cogeneration and District Heating ...................................... 15

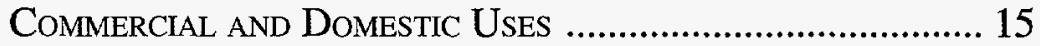

Evaluating Clean Coal Technologies .................................... 17

The Evaluation Process ....................................................... 17

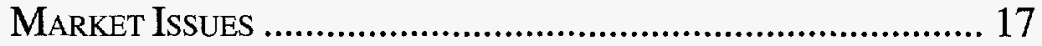

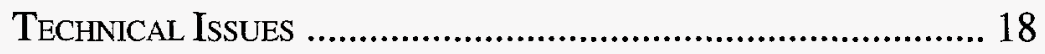

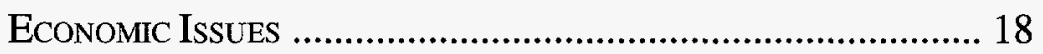

INSTITUTIONAL AND SITING IsSUES ........................................... 19

Where To Go For Help: U.S. GovernMent SERVICES ............ 21

Clean Coal Technology

INFORMATION REQUEST FAXBACK ForM ...................................... 25

\section{ApPendix}

Today's Clean Coal Technologies …………………….......... 27

Precombustion Coal Preparation ........................................ 29

Physical Cleaning .............................................................. 29

Low-RANK UPGRADING ...................................................... 30

Bituminous Coal Preparation ......................................... 31

ECONOMICS AND PERFORMANCE …………………………...... 32

Combustion TeChNologies ...................................................... 33

Fluidized Bed Combustion ............................................... 33

Nitrogen Oxide Controls ................................................... 34

Post-Combustion CleANING ……………………………….... 35

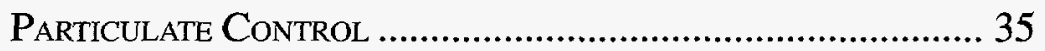

Sulfur DioXIDE ConTROL ................................................. 35

Nitrogen OXIDE Control ............................................... 36

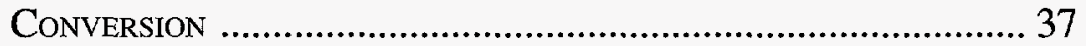

IntEgrated Gasification Combined CyCle .......................... 38

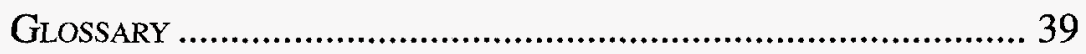



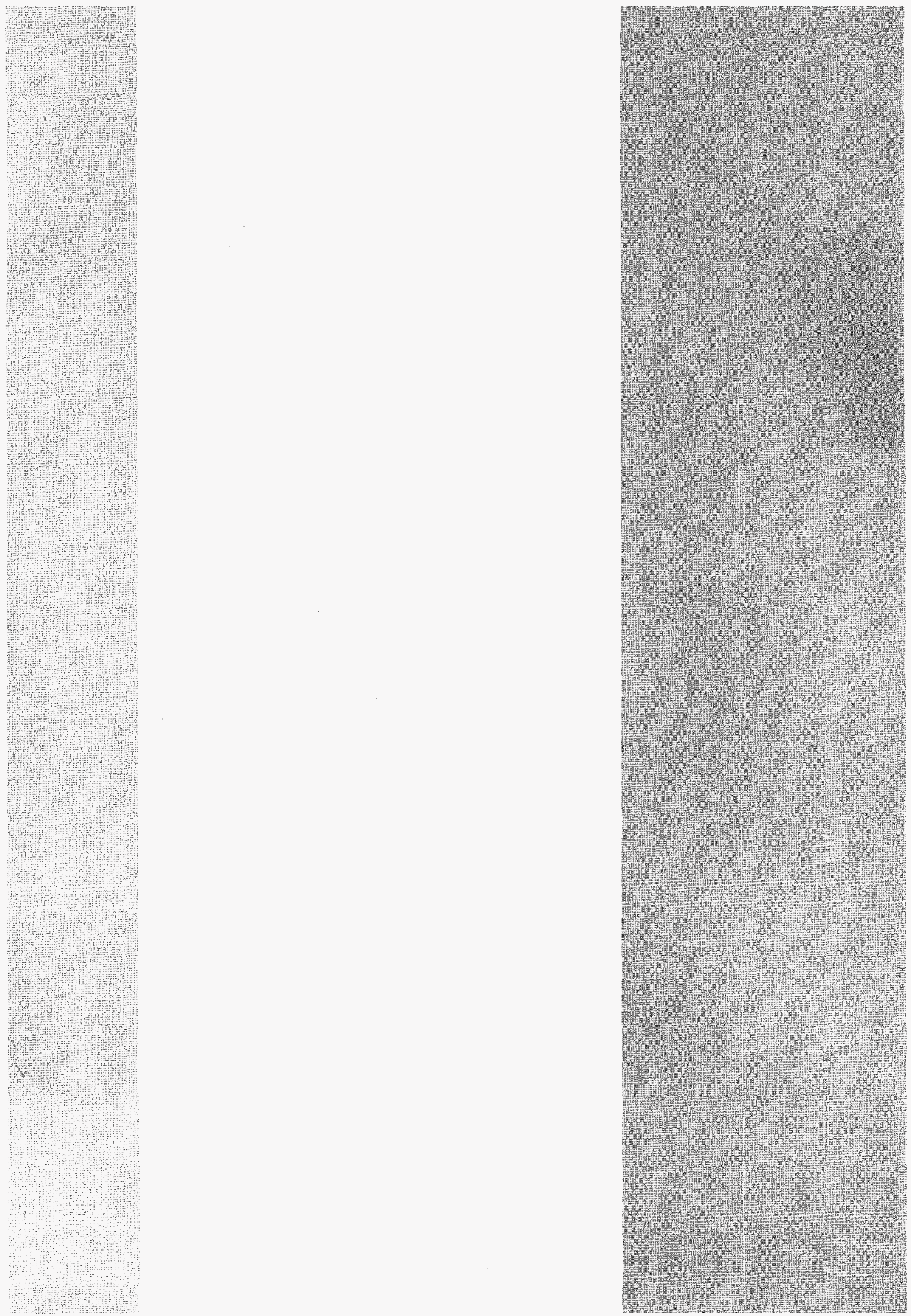


\section{DISCLAMIER}

Portions of this document may be illegible in electronic image produets. Images are produced from the best available original document. 



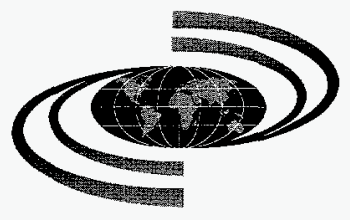

Dear Colleague:

Reliable commercial energy supplies, particularly electricity, are crucial to the economic and social development of any society. Coal has many advantages which ensure that it will play a vital role in meeting energy needs throughout the world. Coal is the world's most plentiful fossil fuel. It is geographically widespread and found on every continent. Reserves are sufficient to last into the 22nd century. Costs are reasonable and free from volatile price swings. These advantages, however, are often counterbalanced by increasing concerns over the environmental impacts of fossil fuels.

Today's clean coal technologies permit environmentally-sound, economic and efficient use of coal. These technologies are expected to play a crucial role in satisfying the parallel needs for energy growth and environmental protection well into the next century. The United States has developed a range of clean coal technologies which can meet the world's needs. These technologies include systems for precombustion coal cleaning, combustion control, post combustion clean-up and coal conversion. They are available for retrofit, repowering and new applications in the electric power and other sectors.

This publication, "Sustainable Development with Clean Coal," has been developed to help stakeholders throughout the world to identify and begin to evaluate currently-commercial clean coal technologies for their specific applications.

Factors unique to each situation such as coal quality, environmental requirements, the plant site, costs, and financing terms typically influence the choice of technologies. This publication describes the options and lays out a five-point process which can serve as a general framework for evaluation.

We hope that this information is helpful to you. Your views are very important to us. Hence, we have provided a facsimile form in this publication for suggestions or questions concerning the information it contains.

Sincerely,

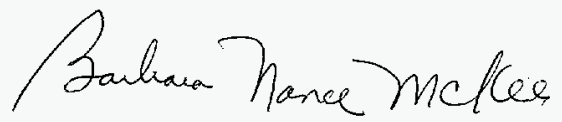

Barbara McKee, Director

Office of Coal and Power Import and Export

Office of Fossil Energy

U.S. Department of Energy 

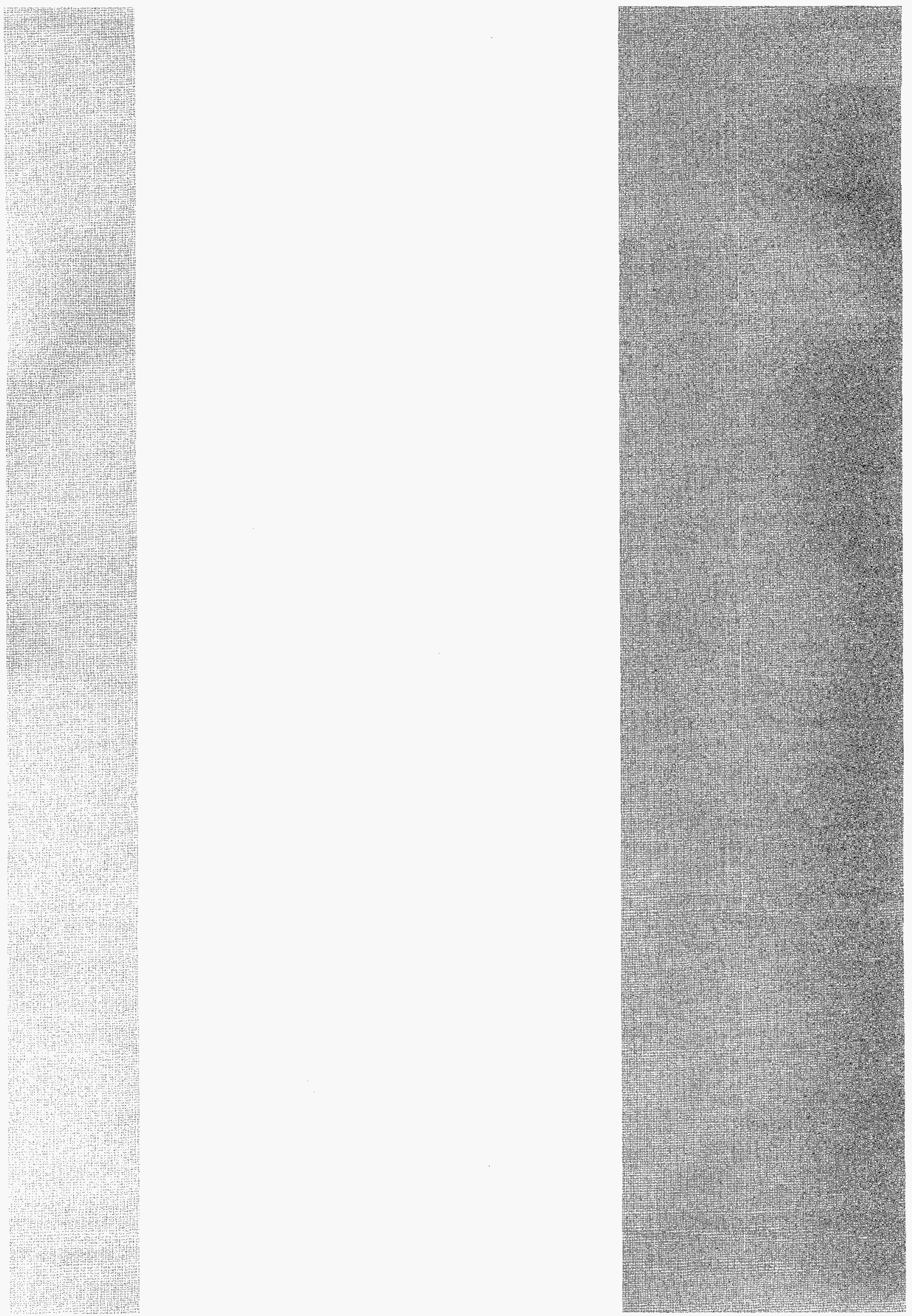


\section{Sustainable DeVelopment with Clean Coal}

O lean coal technologies represent a fundamental change in the way coal is utilized. They allow cleaner, more efficient coal use than conventional coal utilization technologies. In many cases, they help minimize environmental impacts while achieving overall cost improvements. The increased application of clean coal technologies offers a bright future for coal use throughout the world.

Coal is the world's most plentiful fossil fuel. It is found on every continent, and recoverable reserves are sufficient to last well into the 22 nd century. A quarter of the primary energy consumed worldwide comes from coal. And, more than a third of the world's electricity is produced in coal-fired power plants. This share is projected to continue through 2015.

Abundant and typically inexpensive, coal is a key domestic energy resource in many countries. Even after the sharp decline in global oil and gas prices of the mid-1980s, coal remained the least expensive fossil fuel for many countries. Today, as economies grow and energy needs increase throughout the world, the demand for coal is expected to rise as well. Currently, 4.6 billion metric tons of coal are consumed annually worldwide. By 2015, consumption is expected to reach between 5.6 and 7.9 billion metric tons. This projected increase in coal use comes at a time when many nations are addressing environmental concerns. Unfortunately, uncontrolled use of coal leads to major emissions of pollutants, which can harm human health, cause material damage, and degrade the natural environment. In response, many countries are developing and enforcing strict environmental standards. Moreover, international development institutions such as the World Bank and regional development banks link their project funding to compliance with environmental standards.

The parallel growth in energy demand and environmental concern has sparked interest in technologies that burn coal with greater efficiency and fewer emissions. Clean coal technologies will ensure that continued use of the world's most abundant energy resource is compatible with a clean, healthy environment.

\section{World Proved Reserves Of Coal Compared To Oll And Gas}

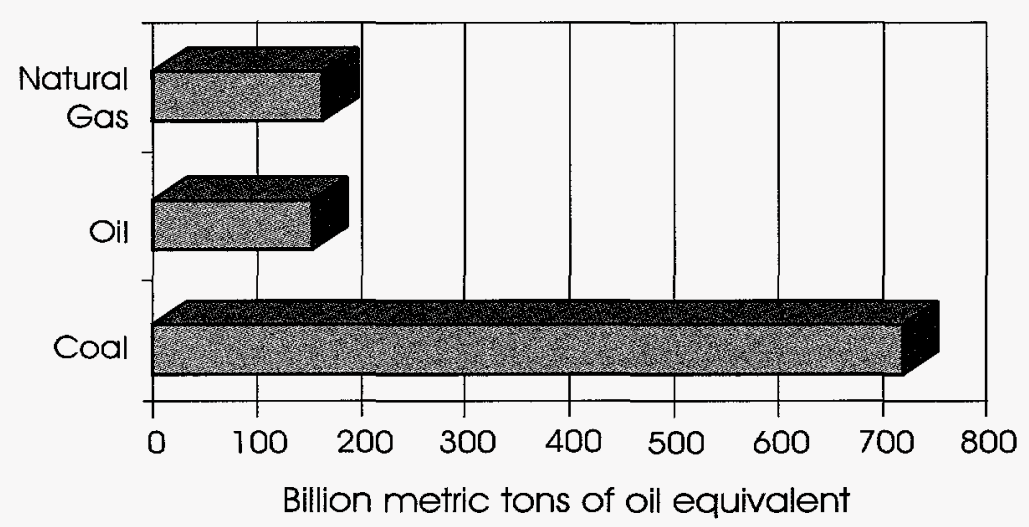



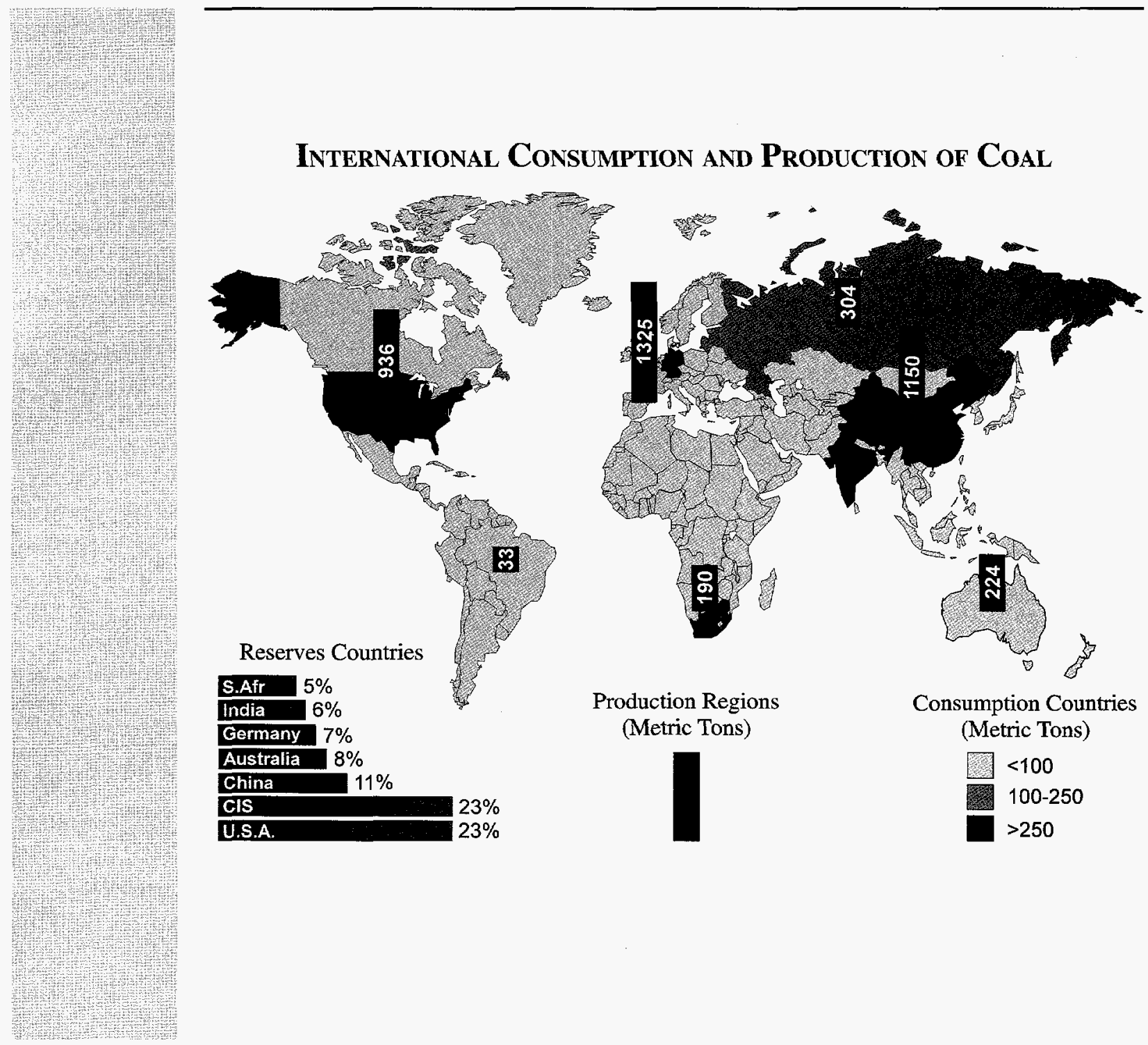

\section{Coal Facts}

- Coal has its origins in plants that grew in swamps, millions of years ago. Geological processes working over vast spans of time compressed and altered the decaying plants, increasing the percentage of carbon present. There are four different ranks of coal: lignite (the softest), subbituminous, bituminous, and anthracite (the hardest).

- Along with carbon, scattered atoms of hydrogen, oxygen, nitrogen, and sulfur are also present in coal. In fact, coal contains traces of virtually every mineral on earth today.

- Coal seams range in thickness from a few centimeters to more than 30 meters. Geologists estimate that 3 to 10 meters of compacted plant matter accumulated to form each meter of coal.

- The energy in coal ranges from an average of 11,600 kilojoules $(\mathrm{kJ})$ per kilogram $(\mathrm{kg})$ for lignite to about $34,300 \mathrm{~kJ}$ per $\mathrm{kg}$ for some bituminous coals.

- Using an average of $25,500 \mathrm{~kJ}$ per $\mathrm{kg}$, a metric ton of coal contains the same energy as 623 cubic meters of natural gas, 600 liters of distillate fuel oil, or 3.7 cubic meters of seasoned hardwood. 


\section{Clean Coal Technologies - An Opportunity For Today}

$\mathrm{C}$ lean coal technologies form the foundation for a new generation of coal-fired power plants and industrial facilities. These technologies enable coal utilization to be extremely clean, greatly reducing concerns about many pollutants and dramatically reducing the emission of greenhouse gases.

Clean coal technologies were largely developed in the United States in response to environmental concerns over sulfur and particulate missions. In the 1970s, flue gas desulfurization units were widely installed in new U.S. power plants. Baghouses and electrostatic precipitators were also used to limit the amount of particulate matter released into the atmosphere.

By 1985, concerns about acid rain prompted the U.S. and Canadian governments to develop an environmental strategy addressing the problem. This joint effort led to the U.S. Department of Energy's (DOE) Clean Coal Technology Demonstration Program, which looks for cost-effective ways to limit emissions of sulfur and nitrogen oxides. In 1992, the U.S. government set an annual nationwide limit of 8 million metric tons of sulfur emissions by the year 2000. This requirement put many clean coal technologies on the fast track from the laboratory to demonstration to commercial status.

Today, clean coal technologies can substantially reduce the environmental impacts of coal use. Already in the United States, these technologies have significantly decreased sulfur and particulate emissions while limiting increases in other pollutants such as nitrogen oxide and carbon dioxide.

\section{Avoming the Greenhouse Effect}

Earth's temperature is regulated largely by atmospheric gases. Carbon dioxide $\left(\mathrm{CO}_{2}\right)$, methane, and other gases allow the sun's energy to penetrate to the earth while trapping heat radiated from the earth's surface. This phenomenon is termed the "greenhouse effect." Key questions about the greenhouse effect are still unanswered - such as the role fossil-fuel combustion plays in the release of greenhouse gases, and the effects of global deforestation. Worldwide coal combustion contributes to approximately 37 percent of the total worldwide release of $\mathrm{CO}_{2}$, which constitutes half of the greenhouse gases.

Energy-efficiency investments and technological improvements like clean coal technologies offer reductions in $\mathrm{CO}_{2}$ emissions. Many clean coal technologies are effective in reducing $\mathrm{CO}_{2}$ because they increase power generating efficiencies. In higher-efficiency systems, less $\mathrm{CO}_{2}$ is produced per unit of fuel consumed. For example, commercial clean coal technologies like fluidized bed combustion and gasification combined cycle boost generating efficiencies into the 40 to 45 percent range. This can reduce $\mathrm{CO}_{2}$ emissions by 17 to 27 percent.

Further U.S. development of clean coal technologies will push operating efficiencies even higher. Improvements in gas turbine technology will enable coal gasification combined cycle systems to achieve efficiencies higher than 50 percent. 
These same successes can be achieved in other countries as well. DOE's Clean Coal Technology Demonstration Program has accelerated the ongoing commercial use of clean coal technologies, while reducing many of the risks and uncertainties associated with technology development. As a result, U.S. clean coal technologies are well-proven and widely applied. For example, flue gas desulfurization units have been installed in many power plants throughout the world and fluidized bed combustion systems are being used in Central Europe to burn the high-sulfur coal of that region.

Clean coal technologies are well suited for a wide range of applications. For example, power plant construction has changed in many countries from conventional units of 500 to 1,000 megawatts to high-efficiency units of 100 to 300 megawatts. This shortens the construction period and provides two key benefits: lower financing costs, and increased ability to match changing demand patterns. Clean coal technologies can be utilized in all of these sizes. Modular clean coal technologies such as fluidized bed combustors, which retain their high efficiencies at small sizes, are particularly suitable for these applications. Fluidized bed combustion systems developed by U.S. companies already supply systems worldwide, and dominate the market for this technology. Similarly, U.S. companies supply nitrogen oxide control technologies, such as specially-designed burners and combustion control systems, to plants around the world.

In many countries, such as those in Eastern and Central Europe, dependence on older coal-fired power plants with little or no pollution control creates a need for retrofit applications. Flue gas desulfurization systems and baghouses can be costeffectively installed in the older, more polluting plants.

Clean coal technologies can be used in three different ways, or in a fourth manner that converts coal into clean fuels:

- Pre-combustion,

- Combustion,

- Post-combustion, and

- Conversion.

\section{Pre-combustion technologies - clean} the coal before it is burned. Removal of ash, sulfur, and other trace minerals from the raw coal lessens the need for pollutant control during or after combustion. It also increases the amount of available energy from a delivered volume of coal. Removing matter that does not add to coal's heating value lowers costs for transporting the coal, maintaining the boilers, and cleaning the exhaust gases.

\section{From The Laboratory...}

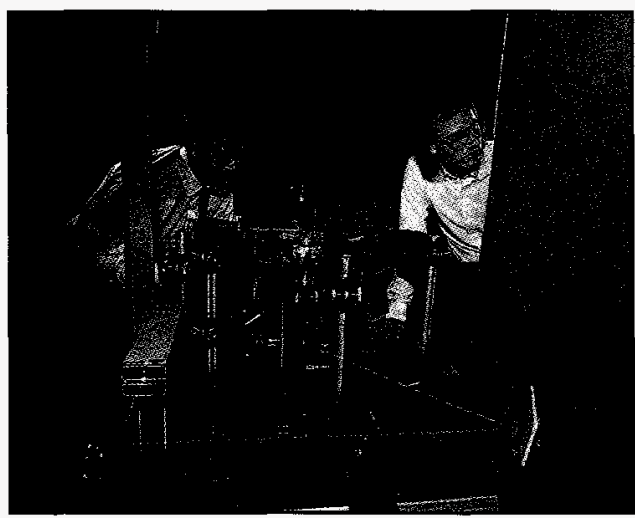

Many clean coal concepts began as laboratory experiments.

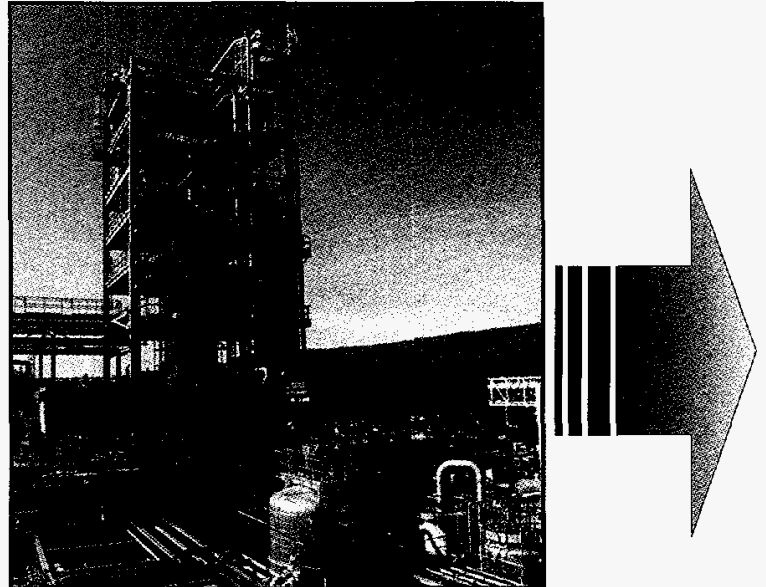

Pilot plants were built to test the most promising concepts. 
2. Combustion technologies - remove pollutants inside the combustor or boiler while the coal burns. These technologies control combustion so that fewer pollutants are emitted in the exhaust gases. The fluidized bed combustion technology mixes a sorbent chemical, such as limestone, in with the coal to remove sulfur oxides in the combustion process. Other technologies control the fuel/air mixture and combustion temperature to limit the formation of nitrogen oxide.

3. Post-combustion technologies - reduce the amount of particulate, sulfur oxides, and nitrogen oxides in the equipment leading to the stack. Baghouses and electrostatic precipitators capture particulates, flue gas desulfurization systems limit sulfur emissions, and selective catalytic reduction units minimize nitrogen oxide emissions.

4. Conversion technologies - bypass the combustion process altogether, changing coal into a clean gas or liquid that can be used as fuel. In a gasification process, coal is converted to a fuel gas that is similar to natural gas and can be burned in a gas turbine. Conversion allows pollutants in the coal to be removed economically and effectively prior to combustion.

\section{Fuel Chain}

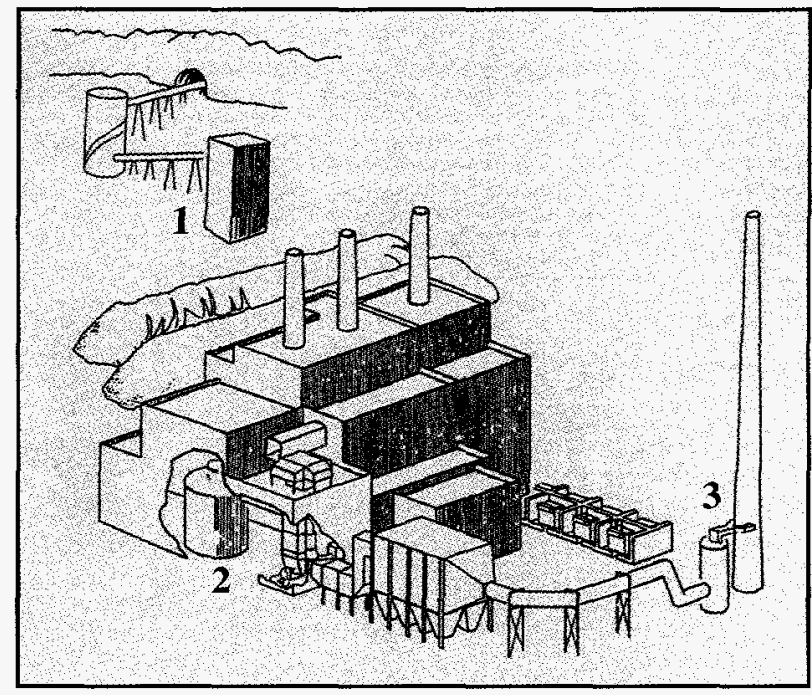

Coal can be cleaned at several points in its "fuel chain": (1) in the preparation plant, (2) inside the combustor, or (3) at the stack. Another category of clean coal technology replaces the traditional coal combustor with a coal gasifier or other conversion process.

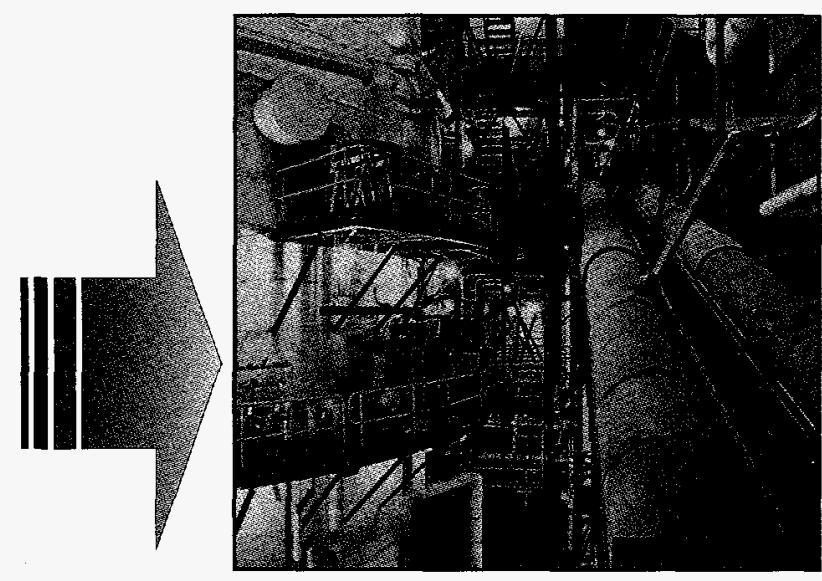

The best of the new technologies were demonstrated in the U.S. Department of Energy Clean Coal Technology Program.

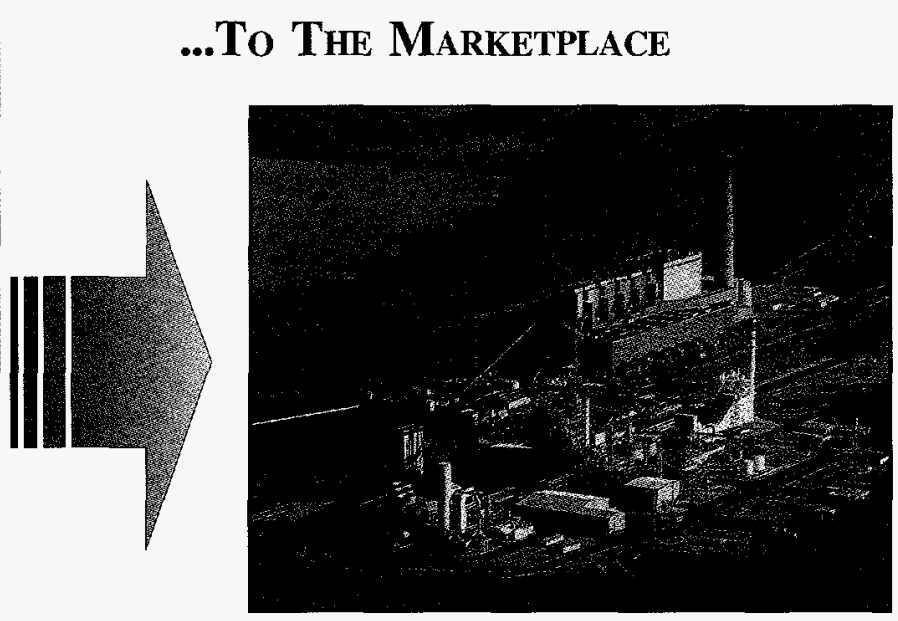

Technologies, such as gasification combined cycle, became commercial. 


\section{DOE's Clean Coal Technology Program}

The U.S. Department of Energy's (DOE) Clean Coal Technology Program researches, develops, demonstrates, and commercializes cost-effective solutions to environmental issues associated with coal use. This joint effort by government and industry has been in operation since 1985 .

The program was initiated in response to a bilateral agreement between Canada and the United States to address acid rain. Faced with the need to reduce sulfur dioxide and nitrogen oxide emissions, the U.S. Congress directed DOE to run a competition for clean coal technology projects.

At year-end 1996, the program had completed 18 projects, with applications ranging from coal cleaning to more efficient combustion and post-combustion technologies, to improved pollution-control processes. The program has accelerated the commercialization of these technologies by demonstrating their effectiveness in reducing pollution emissions and increasing process efficiency. Project developers can review a menu of practical, clean coal technology options and determine which is most appropriate for their needs.

U.S. industry has played a key role by providing technologies as well as over 60 percent of total project funding. Through this active involvement, U.S. companies have gained valuable experience in designing, constructing, and operating clean coal technologies and making them available worldwide.

Through early 1997 , U.S. clean coal technologies have demonstrated the capacity to provide low-cost energy for use in an environmentally responsible manner. The benefits from these technologies will expand and evolve as progress continues in the DOE program. 


\section{The Benefits Are Real}

A tmospheric emissions arise primarily as the by-products of coal combustion, namely particulates, sulfur oxides, and nitrogen oxides. Clean coal technologies offer a wide range of control capabilities for all of these pollutants in a broad range of power generating and industrial applications. They can be incorporated into an initial plant design or added later, enabling efficient and clean coal use for both new facilities and those already on-line.

Particulate matter is often a high priority in pollution control. Among the effects of uncontrolled particulate emissions from coal-fired facilities are impaired visibility, soiling of surrounding areas, aggravation of the effects of sulfur oxides, and human respiratory problems. Fortunately, the use of baghouses and electrostatic precipitators can remove most particulate matter at relatively low costs.

Sulfur oxide emissions also have an immediate, detrimental impact on the environment and quality of life. In the presence of particulate matter, sulfur oxides contribute to human respiratory problems, reduced visibility, materials corrosion, and degradation of vegetation. In the presence of moisture in the atmosphere, sulfur oxides have been identified as contributing to acid rain. Several clean coal technologies, including flue gas desulfurization and fluidized bed combustion, have been widely used commercially to lower sulfur oxide emissions.

Clean coal technologies also reduce nitrogen oxide emissions. Nitrogen oxides have been associated with respiratory disorders, corrosion, and damage to vegetation. They have also been identified as a precursor to ozone and smog, and play a large role in the formation of acid rain. Clean coal technologies can be used to limit the formation of nitrogen oxides during combustion or convert them to harmless compounds in combustion exhaust gases.

\section{The Major Pollutants From Coal Combustion}

Three major pollutants are released when coal burns: particulates, sulfur dioxide, and nitrogen oxides.

Particulates. Particulates are the solid matter that remain after coal is burned. They include ash-forming materials mixed in with the coal, particles of unburned carbon, and solidified pieces of condensed compounds that form as exhaust gases cool. Size and properties of particulate matter vary according to the type of coal used and the way in which it is burned.

Sulfur Oxides. Sulfur exists in coal two in forms - pyritic and organic. In the pyritic form, sulfur is combined with iron in finely dispersed particles that are physically distinct from the coal. In the organic form, sulfur is chemically bound to the carbon atoms of the coal. In some coals, pyritic sulfur can account for as much as 70 percent of total sulfur content; in other coals, organic sulfur dominates. Combustion releases both types of sulfur in a reaction with air that creates sulfur dioxide.

Nitrogen Oxides. Like sulfur, nitrogen molecules are trapped in coal. When coal burns, this fuel-bound nitrogen is released as nitrogen oxides $\left(\mathrm{NO}_{x}\right)$. Combustion also creates $\mathrm{NO}_{x}$, which forms when molecular nitrogen is "pulled" from the air and recombined with oxygen by high-temperature combustion, typically $1,650^{\circ} \mathrm{C}$ or more. 
The value of clean coal technologies is not limited to improved pollution control. Other benefits include higher thermal efficiencies, greater fuel flexibility, and lower long-term operating risks.

For many new plants, use of clean coal technologies boosts a plant's thermal efficiency while reducing emissions. Technologies such as fluidized bed combustion and integrated gasification combined cycle allow plants to operate at high efficiencies, extracting 45 to 50 percent of the available energy from coal. In contrast, conventional plants extract roughly 33 percent of the energy from coal.

This higher performance efficiency means that the plant needs less fuel to supply power or steam, which not only reduces pollutant emissions, but lowers fuel costs. Consequently, plants equipped with clean coal technologies can provide competitively priced electricity.

Some clean coal technologies also increase fuel flexibility. Conventional pulverized-coal power plants are designed to burn a specific type of coal. The boilers, economizers, coal-handling equipment, and particulate-control systems are all sized to accommodate the coal's particular physical and chemical properties. Clean coal technologies, such as fluidized bed combustion and integrated gasification combined cycle systems, allow greater flexibility in the type of coal the plant can effectively use. The ability to burn different coals allows a plant to take advantage of changes in both the availability and price of coal.

In most conventional plants, switching to a different coal type creates the risk of generating less electricity from the boiler and increasing boiler maintenance. For example, burning a different coal type can expose surfaces inside the boiler to scaling and also require readjustments to air and fuel balances, which can sacrifice operating efficiencies. Although changes in coal may require operating adjustments in some types of clean coal technology applications, the impact on plant performance is much less severe.

\section{Benefits from Clean Coal Technology in the United States}

In 1971, the U.S. government set health and welfare standards for ambient emissions of sulfur dioxide $\left(\mathrm{SO}_{2}\right)$, nitrogen oxides $\left(\mathrm{NO}_{\mathrm{x}}\right)$, and several other pollutants which made the use of clean coal technologies increasingly necessary. Specific emission limitations were announced in 1978 to require that new coal-fired power plants emit no more than 0.52 grams of $\mathrm{SO}_{2}$ per megajoule of coal consumed. $\mathrm{SO}_{2}$ emissions standards were further tightened in 1995 and by the year 2000 will limit nationwide utility $\mathrm{SO}_{2}$ emissions to half of what they were in 1986.

In 1990, the U.S. government set a goal of reducing nitrogen oxide emissions 1.8 million metric tons below 1980 levels. On average, this emission standard will require power plants to reduce nitrogen oxide concentrations in exhaust gases to below 1 gram per cubic meter.

The effectiveness of clean coal technologies has been demonstrated in the U.S. through the successful overall reduction of sulfur and particulate emissions and a decrease in nitrogen oxide emissions from power plants. Between 1970 and 1994, sulfur emissions declined 25 percent despite an increase in coal consumption of over the same period. This improvement was largely due to the effectiveness of flue gas desulfurization units. The expanded use of baghouses and precipitators was largely responsible for a 20 percent decline in particulate concentrations between 1985 and 1994. 


\section{Clean Coal Technologies For New Power Plants}

New power plants are needed throughout the world to meet growing needs for electric generating capacity. Frequently, the high demand for power needed to keep pace with economic development has encouraged the construction of power plants with poor environmental performance, directly affecting the quality of life. Fortunately, the successes in designing and constructing new plants with clean coal technologies can be used in other countries to meet growing demand for efficient and clean coal-fired plants.

A plant that cleanly and efficiently burns a range of coal types provides many environmental, operating, and risk advantages. Since fuel represents a large portion of a plant's life-cycle costs, efficiency improvements and fuel flexibility can enhance a plant's financial return. In an era of increasing privatization and competition in the power generation industry, plant operating costs - not just initial capital costs - are becoming more important.

The feasibility of clean coal technologies depends largely on a plant's operating requirements. For new plants, these technologies should be considered concurrently with other design issues such as capacity, available coal types, space restraints, construction and operating costs, and emission levels. For a detailed discussion of feasibility issues, see "Evaluating Clean Coal Technologies" on page 17. All of the clean coal technologies discussed in the Appendix are suited for incorporation into a new plant.

Commercial clean coal technologies offer a menu of options that can be matched to the requirements of a new plant. Coal cleaning techniques, combustion technologies, and pollution-capture equipment can be used independently or together to comply with emission limits and cost constraints.

Most coal-fired power plants burn pulverized coal. These plants grind the coal to the consistency of flour and inject a coal/ air mixture into a pulverized coal boiler, which burns the mixture at very high energy-release rates to produce steam. Pulverized coal plants can be equipped with supercritical steam generators, which offer higher thermal efficiencies than

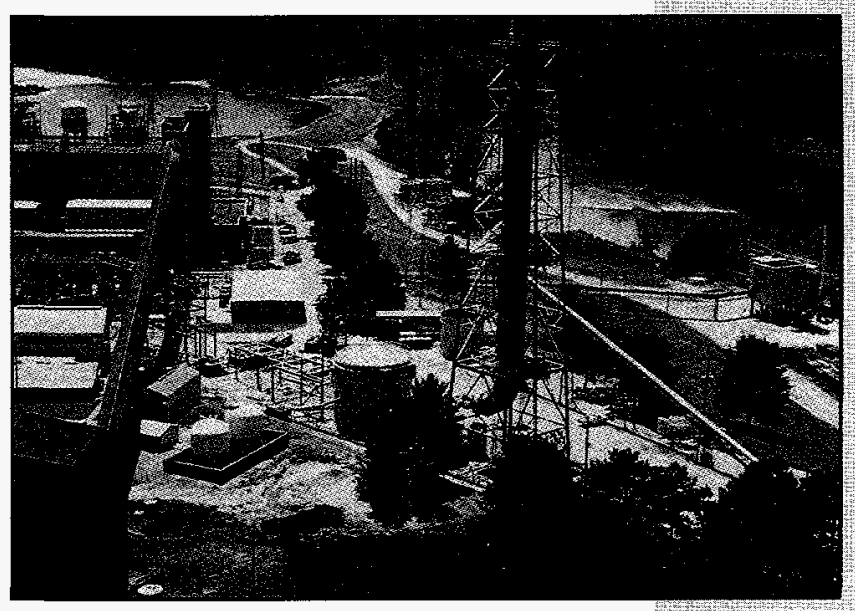

Shown here, during the construction of Georgia Power Company's Plant Yates, is Southern Company Services, Inc. flue gas desulfurization equipment which eliminates most sulfur oxide emissions. conventional generators. When equipped with clean coal technologies, pulverized coal plants are able to meet most environmental standards. U.S. companies have installed flue gas desulfurization systems, baghouses, and selective catalytic reduction systems on these plants worldwide. 


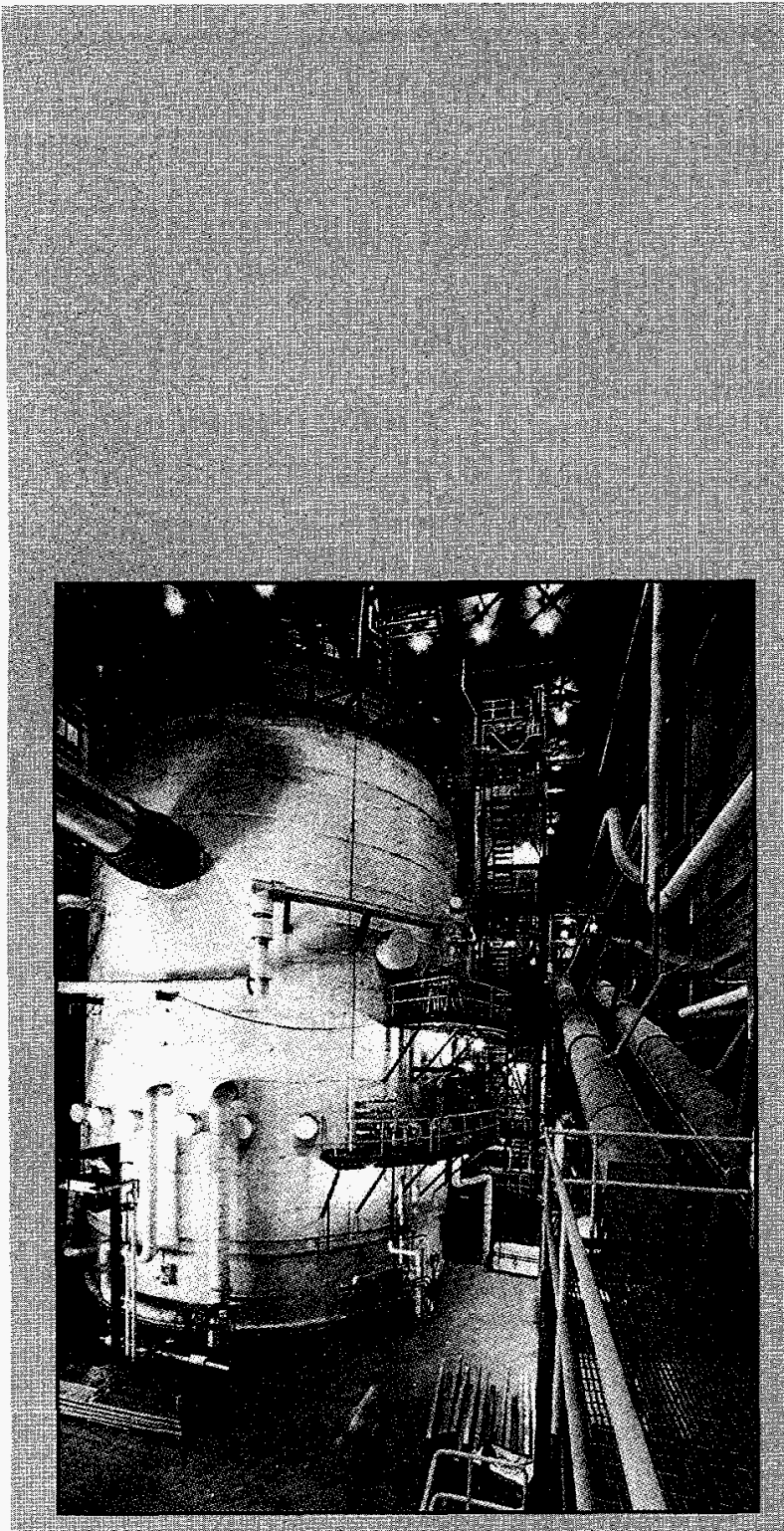

The pressuriaed flidized bed boller system at the Ohio Power Company S Tdd PFBC Denonstration Projed is the cleanest nost advanced of its type currently operating in the world.
Other technologies for new plants, such as fluidized bed combustion and integrated gasification combined cycle systems, have higher initial costs; however, they are offset by lower operating costs, increased fuel flexibility, and saleable by-products.

Fluidized bed combustion technology burns coal or other fuel within a mixture of limestone or inert materials that is suspended over jets of air. This turbulent mixture of air and materials produces a fluidized "bed" which provides efficient combustion with relatively low emissions of sulfur and nitrogen oxides.

Where fuel flexibility is a driving concern, fluidized bed combustion systems are particularly advantageous. These systems are able to burn a much broader range of coal than conventional systems. Additionally, fluidized bed combustion plants that have access to opportunity fuels, such as coal wastes and petroleum coke, can use these low-cost fuels to bring down operating costs.

In an integrated gasification combined cycle power plant, coal is converted in a gasifier to a clean combustible gas and used to fuel a combined cycle plant. Although these plants have comparatively high initial costs, they readily meet environmental requirements and are more efficient than pulverized coal, stoker, and atmospheric fluidized bed power plants. In addition, high quality sulfur is a recoverable byproduct of cleaning the fuel gas following the gasification process. Marketing this by-product can increase the return on plant investment.

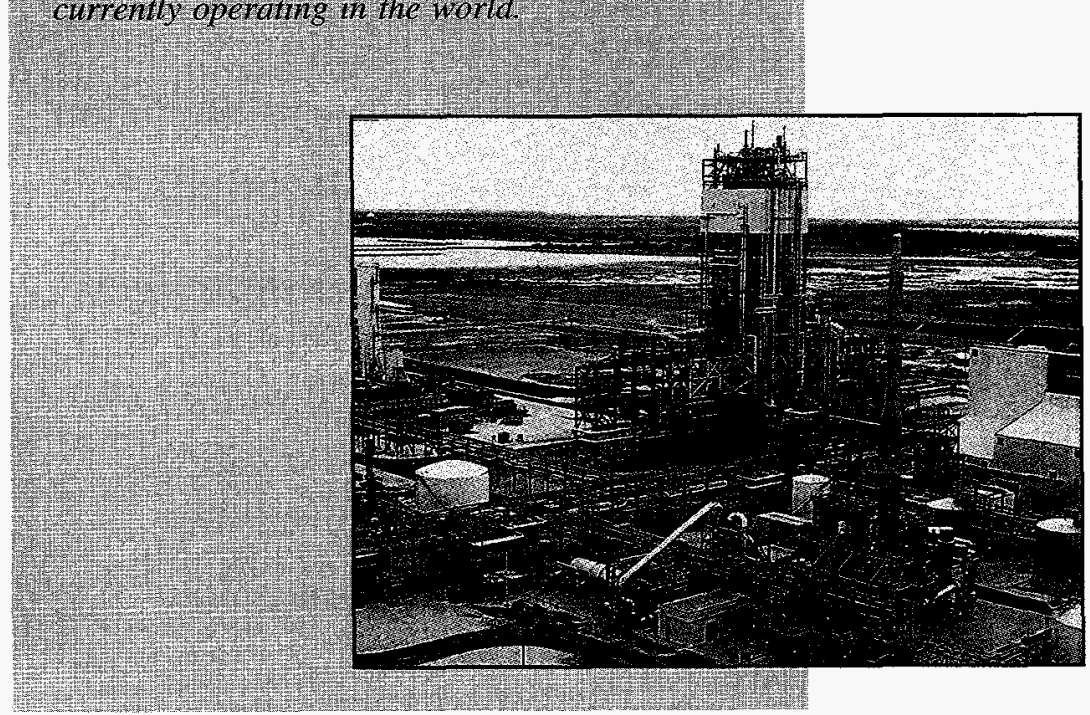

The IGCC system at Tampa Electric Company's Polk Power Station is expected to achieve a thermal efficiency of $40 \%$, thereby emitting less carbon dioxide and decreasing global warming concerns. 


\section{Clean Coal Technologies For Existing Power Plants}

$\mathrm{M}$ any countries have fuel-fired power plants that require upgrading to improve plant economic or environmental performance. Two broad classes of upgrade options are available. Retrofit options involve installing modern pollution control devices without making major changes in plant design. Repowering options replace all or part of outmoded power generating equipment with modern systems. Many clean coal technologies provide attractive retrofit and repowering options.

\section{Retrofit Options}

Retrofits are a cost-effective way to improve the environmental performance of an existing power plant. While retrofits are generally not as effective as many repowering technologies, they offer cost-effective pollution-reduction measures with significantly less impact on plant operation. They are usually less extensive than repowering efforts in terms of plant downtime.

Retrofit efforts are often the most practical method for complying with tightened emissions regulations. In response to the need for low-cost pollution measures, U.S. companies have worked with coal-fired power plants throughout the world to install retrofit equipment.

\section{Clean Coal Technologies Retrofit Applications*}

\begin{tabular}{|c|c|c|}
\hline & Pollutant Reduced & Description \\
\hline \multicolumn{3}{|l|}{ Combustion Methods } \\
\hline Gas Reburning & $\begin{array}{l}\text { Nitrogen } \\
\text { Oxide }\end{array}$ & $\begin{array}{l}\text { Increases the fuel/air ratio above the combustion zone promoting the } \\
\text { conversion of } \mathrm{NO}_{\mathrm{x}} \text { to molecular nitrogen. Minimizes } \mathrm{NO}_{\mathrm{x}} \text { emissions. }\end{array}$ \\
\hline Low- $\mathrm{NO}_{\mathrm{x}}$ Burners & $\begin{array}{l}\text { Nitrogen } \\
\text { Oxide }\end{array}$ & $\begin{array}{l}\text { Promotes a low flame temperature and decreases turbulence around } \\
\text { the flame to limit } \mathrm{NO}_{\mathrm{x}} \text { formation. }\end{array}$ \\
\hline Overfire Air (OFA) & $\begin{array}{l}\text { Nitrogen } \\
\text { Oxide }\end{array}$ & $\begin{array}{l}\text { Introduces air above the combustion zone, which keeps combustion } \\
\text { temperature low and promotes conversion of } \mathrm{NO}_{\mathrm{x}} \text { to nitrogen. }\end{array}$ \\
\hline \multicolumn{3}{|c|}{ Post-Combustion Methods } \\
\hline $\begin{array}{l}\text { Electrostatic } \\
\text { Precipitators (ESPs) }\end{array}$ & Particulates & $\begin{array}{l}\text { Charges ash particles using an electric field, then pulls them onto an } \\
\text { oppositely charged collection surface. }\end{array}$ \\
\hline Bag Houses & Particulates & Uses a fabric or polymer filter to capture solid particles. \\
\hline $\begin{array}{l}\text { Flue Gas } \\
\text { Desulfurization }\end{array}$ & $\begin{array}{l}\text { Sulfur } \\
\text { Dioxide }\end{array}$ & $\begin{array}{l}\text { Adds a sorbent such as limestone into the flue gas to absorb gaseous } \\
\text { sulfur. }\end{array}$ \\
\hline Sorbent Injection & $\begin{array}{l}\text { Sulfur } \\
\text { Dioxide }\end{array}$ & $\begin{array}{l}\text { Injects a sorbent with the coal in the boiler to absorb sulfur during } \\
\text { combustion. }\end{array}$ \\
\hline $\begin{array}{l}\text { Selected Non-Catalytic } \\
\text { Reduction (SNCR) }\end{array}$ & $\begin{array}{l}\text { Nitrogen } \\
\text { Oxide }\end{array}$ & $\begin{array}{l}\text { Injects urea or ammonia into the exhaust gases to convert } \mathrm{NO}_{\mathrm{x}} \text { to } \\
\text { nitrogen and water vapor. }\end{array}$ \\
\hline $\begin{array}{l}\text { Selected Catalytic } \\
\text { Reduction (SCR) }\end{array}$ & $\begin{array}{l}\text { Nitrogen } \\
\text { Oxide }\end{array}$ & $\begin{array}{l}\text { Injects ammonia into the exhaust gases, then relies on a catalyst } \\
\text { to promote the conversion of } \mathrm{NO}_{\mathrm{x}} \text { to nitrogen and water vapor. }\end{array}$ \\
\hline
\end{tabular}

* A more detailed description of these technologies is provided in the Appendix. 


\section{Repowering Options}

Repowering technologies replace a major portion of an existing plant - such as the boiler - with new power generating equipment while retaining other portions of the plant, such as the steam generating equipment. Repowering projects are typically more extensive than retrofits and require a longer period of plant inactivity to upgrade or replace large equipment like turbines, boilers, and economizers.

Repowering is an attractive option when coalfired plants reach the end of their useful lives, typically 25 to 40 years after construction. After years of operation, plant equipment wears to the point where routine maintenance is insufficient to ensure reliable performance. Although a variety of factors are involved, 20 years often marks the point when operating and maintenance costs increase to such an extent that extensive power plant modifications become economically feasible.

Repowering also provides an opportunity to correct for any changes in demand that may have developed since the plant was initially commissioned. For example, to increase power generating capacity, a utility may repower an existing plant to avoid the problems of finding and obtaining approval for a new site. Plants may also need to improve their environmental performance with boiler upgrades. Although pollution control is a key benefit of repowering, a repowered plant can also produce more power - sometimes twice as much or more - than the original plant. This can extend a plant's lifetime by 20 to 30 years.

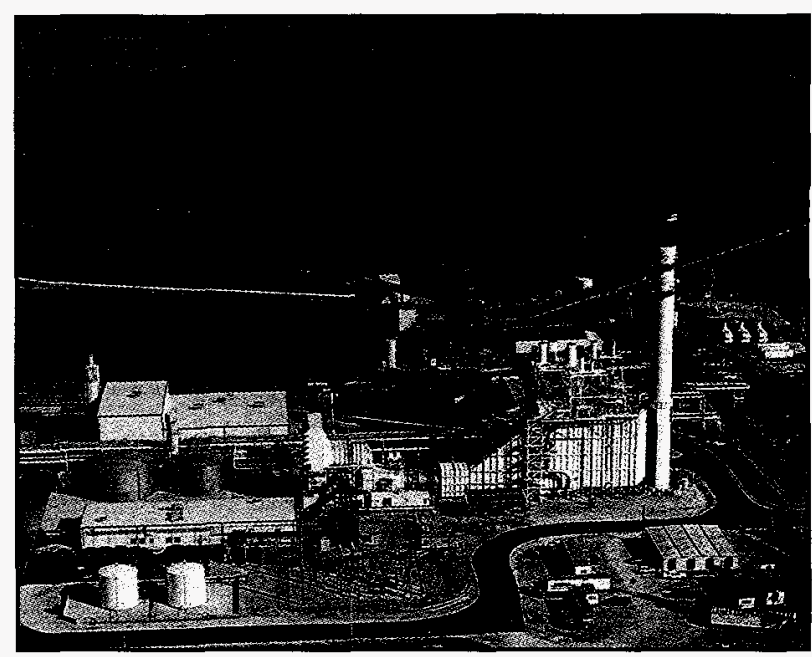

Wabash River's Coal Gasification Repowering Project demonstrates added capacity and improved operating efficiency available from IGCC repowering efforts.

Repowering can also provide an opportunity to change the fuel supply of a plant. A less expensive or more reliable source of coal may motivate a utility to replace an aging boiler with one that is appropriately configured for a different coal type.

Repowering projects exploit the advantages of using standardized, shop-fabricated components. A modular, packaged approach minimizes the costly, customized, on-site construction typical of most conventional technologies. U.S.companies have shared their experience in repowering technologies with coal-fired power plants in several countries in Central Europe.

\section{Clean Coal Technologies Repowering Applications*}

\section{Technology}

Atmospheric fluidized bed combustor (AFBC)

\section{Pressurized fluidized bed combustor (PFBC)}

Integrated gasification combined (IGCC)

\section{Description}

Combines a sorbent with coal in the combustion bed and forces air up through the mixture. Boiler pressure remains roughly atmospheric.

Similar to AFBC except that the boiler pressure is kept between 6 and 16 times atmospheric. The exhaust gases can therefore power a separate turbine.

Relies on coal gasification to provide a fuel gas which is burned in a combustion turbine. The heat of the exhaust gases in turn generate steam, which can power a separate turbine.

\footnotetext{
* A more detailed description of these technologies is provided in the Appendix.
} 


\section{Industrial, Commercial, And Domestic Applications}

$\mathrm{E}_{\mathrm{t} \text { a }}^{\mathrm{a}}$ ach year throughout the world, over 2 billion metric tons of coal is used for industrial, commercial and domestic applications. Coal is used for a variety of manufacturing processes including steel and cement production, and is a valuable raw material for products such as perfume, dyes, insecticides, and medicines. Clean coal technologies offer improvements in the thermal efficiency and environmental performance of these diverse applications. For example, in many industrial applications, energy costs are a significant portion of total operating costs. Efficiency improvements offered by clean coal technologies help decrease energy costs for the industrial application, a definite economic advantage.

Many industrial process emissions also contain substances that can be captured for reuse or for sale as a separate product. The collection and sale or reuse of these substances, through the use of clean coal technologies, add an additional revenue stream to a plant's operation while decreasing overall emissions.

\section{Steelmaking}

An important use of coal in the industrial sector is to produce coke, used in smelting iron ore to make steel. Coke is made by a process called "carbonization" in which a blend of two or more bituminous coals is heated in the absence of air. The coke is then combined with iron ore and limestone in a blast furnace. The resulting carbon monoxide and heat reduce the ore to produce molten pig iron, essential to steel production.

During coke production, the heated coal softens, flows together, and releases pollutants such as sulfur oxides. Many coke ovens have no desulfurization equipment, while others use gas treatment processes more than 30 years old. Clean coal technologies make the coking process cleaner and simpler. In one application, ammonia is captured from coke oven gas and used to scrub hydrogen sulfide from the gas. Using special catalysts, the ammonia is chemically changed into nitrogen and water vapor, and hydrogen sulfide decomposes into elemental sulfur, a saleable by-product. More than 80 percent of the hydrogen sulfide and 98 percent of the ammonia can be removed, along with benzene and other pollutants.

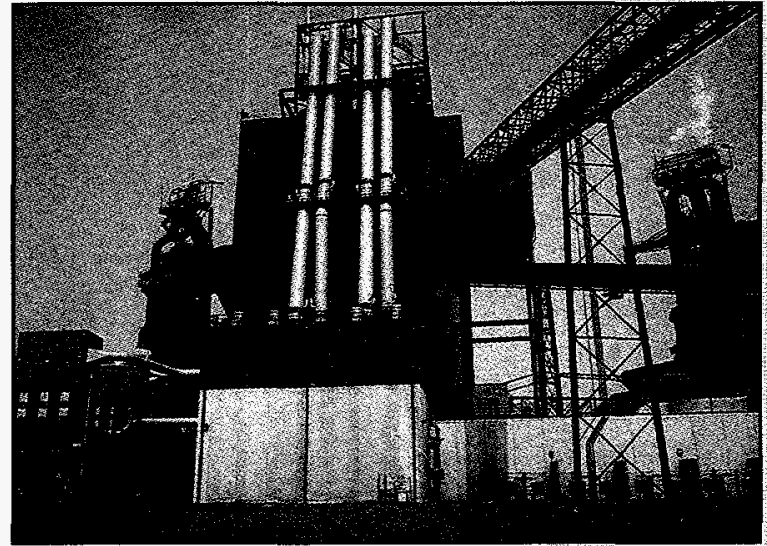

Bethlehem Steel Corporation's Blast Furnace Granulated-Coal Injection System Demonstration Project is one proven industrial CCT application.

Other clean coal technologies provide environmental benefits by reducing the need for coke, lowering the emissions associated with coke production. Technologies, such as granulated coal injection and coal gasification combined with direct iron making, increase the role of coal and decrease the role of coke in iron ore reduction. These processes can be combined with emission control technologies to provide further environmental benefit. 


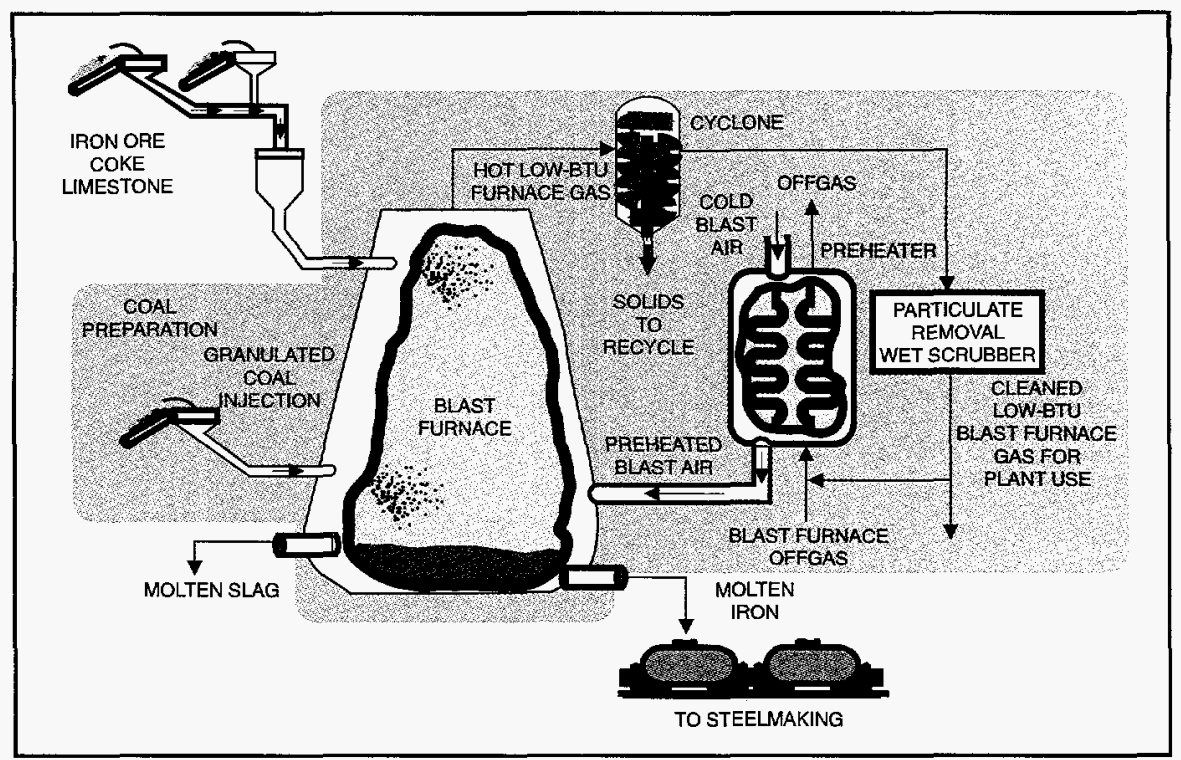

At Bethlehem Steel Corporation, the use of a granulated coal injection system lowers the demand for coke, significantly lowering the emissions of nitrogen oxides and sulfur dioxide assiciated with coke production.

\section{Cement Making}

Cement is made by heating a mixture of limestone, clay, sand, and other minerals in a kiln until they fuse. One innovative clean coal technology uses the waste products from a cement kiln to reduce air pollutants. When the minerals in a cement kiln are heated, they release vapors containing sodium and potassium salts. These vapors later condense as a fine dust. Usually this dust has to be disposed, but a clean coal technology uses the dust to absorb sulfur from the kiln's exhaust gases.

Sulfur-laden kiln gases bubble through a slurry made of the dust and water. Chemical reactions in the slurry remove over 90 percent of sulfur pollutants and produce potassium sulfate, which can be used as a fertilizer. Additional steps recover solid calcium products for reuse in the kiln. Dust collection from kiln heating processes can be improved through the use of electrostatic precipitators and baghouses.

\section{Pulp and Paper Manufacturing}

Pulp and paper manufacturing uses large amounts of energy supplied by coal and by waste streams from the production process. Clean coal technologies can make use of both energy sources. As in other industrial applications, technologies such as fluidized bed combustion, flue gas desulfurization, and particulate capture technologies can improve the environmental performance of coal-fired boilers.

Clean coal technologies can also provide pollution control and greater efficiency in the burning of black liquor, a wood-based waste stream created during the treatment of wood pulp. In many plants, black liquor is sprayed into a furnace and burned to generate steam for electricity and other process heat uses. The byproducts of this combusion include particulate matter, which can be captured with baghouses and electrostatic precipitators. Typically, sulfur dioxide is a relatively small component of the exhaust gases in black liquor combustion. 


\section{Cogeneration and District Heating}

In many countries, coal-fired boilers are used to generate steam for electricity and heat for industrial or domestic purposes. In this cogeneration process, the steam from the boiler is then expanded through a turbine, which powers an electric generator. Waste heat in the steam exhausted from the turbine is recovered and sold to a nearby industrial plant or district heating system. This dual use of steam significantly raises the thermal efficiency of the cogeneration plant - to above 60 percent in many cases.

Cogeneration plants must be located close to end-users of the waste heat. District heating applications are usually located in populated areas. In these cases, the operation of a coalfired plant without pollution control equipment can severely impact the health of the surrounding community.

Clean coal technologies are well-suited to enhance the environmental performance of coal-fired cogeneration plants. Flue gas desulfurization and baghouses can effectively improve air and soil quality around the plants by reducing harmful sulfur dioxide and particulate emissions. Fluidized bed combustion is another attractive cogeneration technology due to its fuel flexibility and comparatively high thermal efficiency. In fact, over 55 percent of total global steam capacity generated by fluidized bed combustion serves cogeneration applications.

\section{Commercial and Domestic Uses}

In many countries, coal provides direct heat for homes and buildings. A number of countries also burn coal for cooking purposes. The environmental consequences of uncontrolled coal use can be substantial. Most smaller coal furnaces and stoves do not have pollution control capabilities. The cumulative effect of using many domestic heaters is large emissions of particulate matter as well as sulfur and nitrogen oxides. Coal cleaning and preparation technologies - such as briquetting - can significantly reduce pollution resulting from this type of coal use.

Briquetting is a process that heats crushed coal particles and then compresses them into blocks. Heating the coal particles to temperatures around $300^{\circ} \mathrm{C}$ prior to briquetting releases much of the moisture and pollutants and softens the coal, allowing further separation of much of the mineral matter. Most coal briquettes are held together with binders, although some coals have sufficiently high clay contents and do not require binders. Briquettes are often made from coal fines - particles typically smaller than 25 $\mathrm{mm}$ - which are collected during coal preparation. Since the crushing process promotes separation of much of the ash-forming minerals, briquettes tend to have a lower ash content than raw coal.

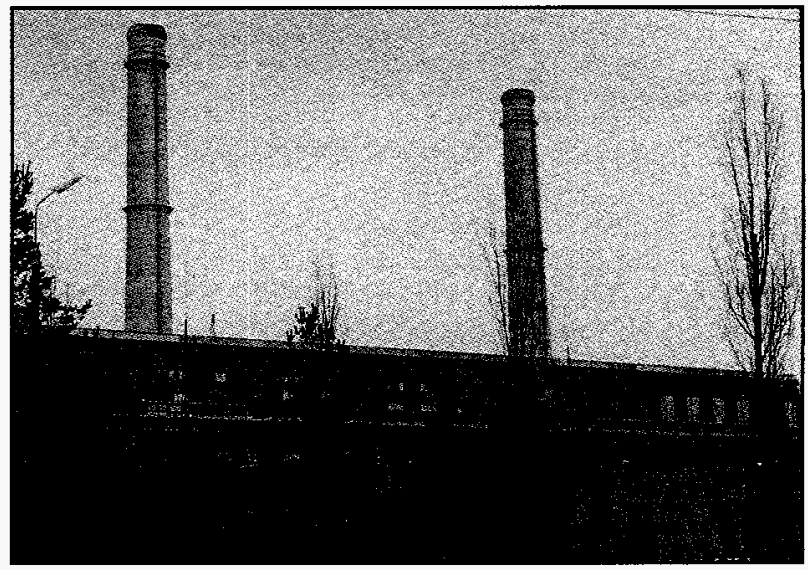

The Skawina Power Plant provides hot water for a Krakow, Poland district heating system. 

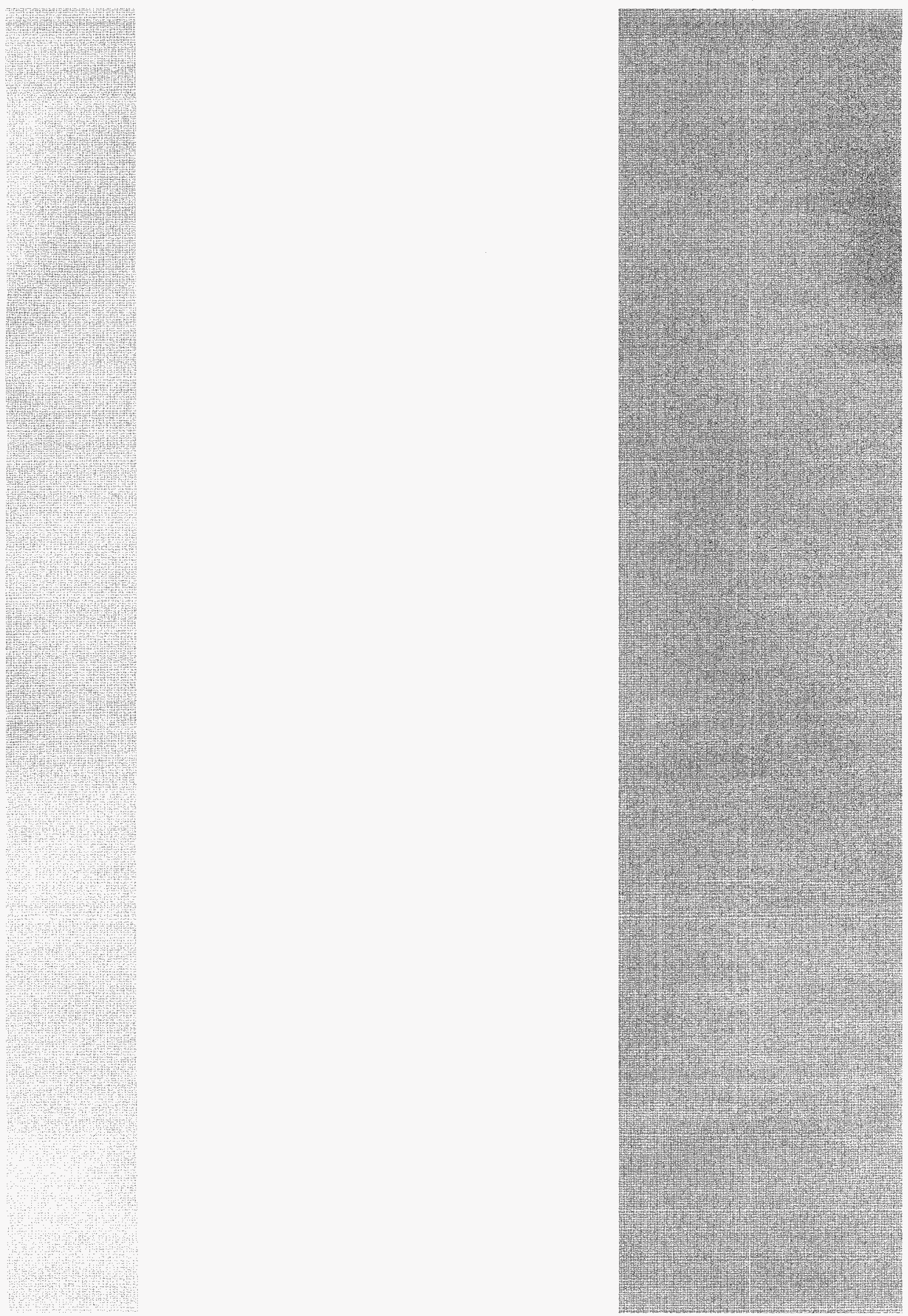


\section{Evaluating Clean Coal Technologies}

B efore making any significant investment in a power plant or large industrial facility, thorough evaluation of technical and economic feasibility should be made. This feasibility analysis must address a variety of market, technical, economic, and siting issues in the context of the specific application.

\section{The Evaluation Process}

The overall evaluation process generally follows five steps:

1. Determine needs. Identify what needs to be accomplished by the project. In the case of clean coal technology projects, these might be:

- Production of electricity and/or thermal energy;

- Higher environmental performance and efficiency; or

- Improved reliability.

2. Identify options to satisfy needs. Determine what types of facilities or equipment could do the job. Identify siting options, if applicable.

3. Evaluate options. Assess siting as well as technical and economic considerations.

4. Select the best option. Perform a comparative analysis using a consistent financial framework to determine which option produces the greatest net benefit.

5. Develop an implementation plan. Develop the budget, schedule, financing, procurement, permitting, and management plan.

Criteria and methodologies for this analysis vary by application and circumstance. All costs are very site-, application-, and design-specific. Actual costs and performance differ from general estimates for broad technology categories. Specific aspects of the evaluation process are described below.

\section{MARKet ISSUeS}

\section{What is needed?}

This is the fundamental question. What market will exist for added output? Is there a need for improvement? Are customers ready, willing, and able to pay the price to cover costs? If not, are credible subsidies available to make up the difference?

\section{How much capacity is needed?}

This determines facility size. Typically, large plants enjoy economies of scale; but smaller plants require less investment, provide flexibility, and can sometimes be built in standardized modules.

\section{How soon?}

Timing is important because it determines whether the facility can be built in incremental modules. 


\section{Technical Issues}

How will the plant be operated?

For power plants, capacity factor is a measure of plant utilization - that is, how close to full capacity will it be operated. It is defined as the amount of power produced over a given time period, divided by the product of the plant capacity and the length of the time period. Higher plant utilization generally allows greater investments to be justified because costs are spread over more production. Power plants designed for peak load applications operate much less often and can only justify lower levels of investment. A plant not built for baseload operation must be specifically designed to be able to change load frequently and quickly.

\section{What types of coal will be used?}

Coals from different sources have widely differing properties that affect how the coal is utilized. These properties also determine potential environmental impacts and which control technologies can be used. Conventional coal technologies were typically designed for the specific properties of coal. Many of the clean coal technologies are more fuel-flexible, allowing the use of lower-cost fuels (within limits). However, if there is an extensive and economical supply of a single coal, fuel flexibility may not be an issue.

\section{What environmental standards apply?}

In most coal-use applications, particulate, sulfur oxide, and nitrogen oxide emissions are the primary environmental concerns. Other issues such as solid waste disposal - particularly for ash and spent sorbent - may also be of concern. Environmental standards are usually set by legal authorities, and in some cases, official sources of financing may also impose certain environmental standards. The potential for tighter restrictions over the operating life of the plant should also be considered.

\section{How will the facility meet those standards?} Clean coal technologies offer environmental solutions that can satisfy the most stringent environmental standards, even given tight technical constraints on the application.

\section{ECONOMIC Issues}

What are the capital costs?

For each option, the costs of the equipment, site preparation, installation, and testing need to be determined. Incremental costs of clean coal technologies must be quantified and balanced against the environmental and efficiency benefits.

\section{What capital budget is available?}

Such a budget may place limits on the size of the facility or type of technology that is feasible. The cost of capital may also vary along with its availability.

What are the operating and maintenance costs? These vary widely by technology. Some clean coal technologies have operating costs that can change with operation, due to the purchase of sorbent chemicals or waste disposal.

\section{What is the thermal efficiency of the plant?} Efficiency plus fuel price determines fuel cost. However, design tradeoffs often must be made between thermal efficiency and capital costs. Supercritical boilers, for example, are more efficient than subcritical boilers, but they also cost more.

\section{What are the fuel costs?}

Fuel costs are typically a large portion of power plant costs, and they are significant for potential clean coal technology applications as well. Uncertainty in fuel costs adds to operating risk, which can usually be mitigated by careful attention to fuel purchase arrangements and by fuel flexibility. For facilities using project finance, a long-term full contract guaranteeing an economic fuel supply is often required by project lenders.

\section{What are the risks?}

Providers of capital will usually do an extensive analysis of risks involved in a new facility. These risks generally fall into the following categories: market, construction, operational, and political. Complex financing transactions may be necessary to mitigate and appropriately share these risks. 


\section{Declining Costs of Commercial Clean Coal Technologies}

The commercialization of clean coal technologies is providing valuable experience in the design, construction, and operation of these systems. As a result, their reliability and efficiency are on the rise, while capital and operating costs are declining. Indeed, the cost of virtually all types of clean coal technologies has dropped rapidly in the 1990s.

These advances are due to knowledge gained from the earlier plants and also to intense global competition among vendors of clean coal technologies. As markets have expanded and become more costsensitive, vendors have responded by standardizing and tightening their designs. Two examples of technologies that have experienced rapid cost decreases coupled with performance improvements are flue gas desulfurization and pulverized coal combustion with environmental controls.

Flue gas desulfurization was first used commercially for power generators in the 1970s. At that time, it was widely considered to be an expensive technology with limited reliability. Over the years, as numerous installations have been put in place, the average cost for flue gas desulfurization at new plants has fallen from above US $\$ 300 / \mathrm{kW}$ to about $\$ 100 / \mathrm{kW}$. In addition, reliability and sulfur removal efficiency have increased significantly. Such units can now cost-effectively reduce sulfur dioxide emissions by 95 percent or more. In addition, the capital cost of a pulverized coal plant with extensive environmental controls has declined from about $\$ 1,500 / \mathrm{kW}$ in 1990 to about $\$ 1,000 / \mathrm{kW}$ today, mostly through standardization and design improvements. These costs are illustrative only and are typical of U.S. sites. Exact capital costs will depend on size, design, construction practices, local costs for labor and commodities, and other site-specific factors. Yet, virtually anywhere today it costs less to build a clean coal-fired power plant than it did only a few years ago.

\section{INSTITUTIONAL AND Siting Issues}

\section{What are the physical site constraints?}

Space restrictions at existing sites can preclude the use of some equipment. Post-combustion flue gas desulfurization systems, for example, can be space-intensive and thus impractical for many applications. Access to cooling water is also essential for many pollution control options. Creative designs can often overcome physical constraints. In fact, many of the technologies demonstrated in the DOE Clean Coal Technology Demonstration Program were specifically designed for plants with physical restrictions.

\section{What permits and licenses are required?}

Large, complex facilities like clean coal technology projects are usually subject to strict regulatory oversight during their planning, construction, and operation. Various permits and licenses must typically be obtained at an early stage. A thorough review of these requirements is a vital step early in the planning process.

\section{What skills are required?}

Advanced systems, such as integrated gasification combined cycle systems, require more training and greater operating skills than conventional systems. A skilled labor force with experience in operating complex processes is key to the effective use of these technologies. Facility management must be structured to attract and retain such skilled personnel.

\section{What supporting facilities are needed?}

Some environmental solutions require materials storage and disposal facilities. Sorbent, ash, and sulfur by-products all require handling, storage, and disposal. The ability of a site to accommodate these needs must be considered. 


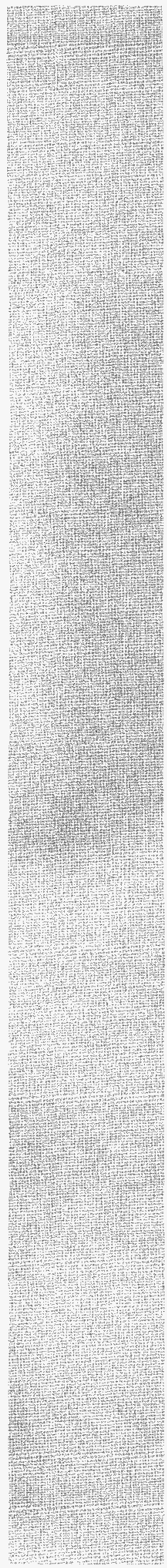

\section{Coal Quality Charactistics}

Coal varies widely in its chemical composition and physical properties. It is primarily a combination of many large hydrocarbons combined in units known as "macerals." The types of macerals present depend largely on the rank of the coal, which is determined mainly by the coal's geological age. A low-rank coal (lignite or subbituminous) is said to be "young" and not subjected to high geological temperatures and pressures as long as "older," highrank coals (bituminous and anthracite). High-rank coals tend to have higher heat content and be less reactive than low-rank coals. Other important coal properties are fixed carbon content, volatile matter content, selling index, ash fusion temperature, and ash composition.

The coal's heat content affects power plant operations since low heat content means that more coal must be mined and transported and that larger equipment (e.g., boilers) may be required. Lignite, called "brown coal" in many countries, typically has a heat content between 11,600 and 16,300 kJ per kilogram $(\mathrm{kg})$. Subbituminous coals have heat contents between 19,300 and 26,750 kJ per kg. Anthracite coals have heat contents within the upper range of bituminous coals but are rarely available in large deposits.

Coal often contains a wide range of impurities such as ash (inorganic materials), chlorine, and sulfur that were incorporated into the coal when it was formed. In addition, ground water intrusion into a coal seam adds moisture and other inorganic materials to the coal. Moisture content is also greatly affected by coal washing or drying. All of these factors influence the combustion properties of the coal. Sulfur content is particularly important as it is the source of sulfur dioxide emissions. Nitrogen oxide emissions, on the other hand, are influenced more by combustion conditions than by the nitrogen content of the coal. Air quality regulations in many countries limit the levels of sulfur dioxide and nitrogen oxide emissions, often requiring special emissions control equipment in power plants and industry. 


\section{Where To Go For Help: U.S. Government Services}

$\mathrm{T}$ he U.S. government offers a wide range of services to assist public and private organizations worldwide who are interested in U.S.-made clean coal technologies. This section describes available assistance and the government agencies providing it. Assistance is coordinated by the Clean Coal Technology Subgroup of the Trade Promotion Coordination Committee, led by the U.S. Department of Energy. A fax form for inquiries is included.

Department of Energy (DOE). The U.S. DOE offers programs that provide information and assistance on U.S. clean coal technologies. The Office of Coal \& Power Import and Export acts as a facilitator between other governments and U.S. industry by supporting: information exchange and dissemination, trade and reverse-trade missions, technology expertise, joint forums, and international agreements. In addition, DOE helps identify opportunities for financing and assists in cordinating activities with other agencies.

Office of Coal \& Power Import and Export

Office of Fossil Energy

Department of Energy

Germantown, MD 20874

Phone: $301-903-3820$

Fax: 301-903-1591

Internet: http://www.fe.doe.gov/international

Agency for International Development (USAID). USAID is the principal U.S. government agency implementing the U.S. Foreign Economic Assistance Program in nearly 100 countries throughout the developing world. USAID commits a loan or awards a grant to an eligible country. The loans and grants fund technical assistance projects and commodity programs that are implemented through the provision of technical assistance services and/or commodities from U.S. suppliers.

Generally, an applicant for assistance must propose an environmentally sound, privately owned and operated project in a USAID-assisted country. The applicant must also be able to demonstrate sufficient financial capability to cost-share expenses. At a minimum, a proposed project must meet the environmental standards of the World Bank and the host country.

An applicant should have prior and current experience with developing, implementing, operating, or owning the type of project it proposes to develop. The project should also provide an opportunity for the export of U.S. goods and services in the course of project development, implementation, and operation. Finally, the applicant must demonstrate either private ownership, or participation in the proposed project through direct or third-party investments. 
USAID

Center for Trade \& Investment Services

USAID, G/EG/CTIS

Washington, DC 20523-0229

Phone: 202-647-1850

Fax: 202-647-8321

Internet: http://www.info.usaid.gov

Department of Commerce/International Trade Administration (DOC/ITA). The ITA is part of the U.S. Department of Commerce's international economic policy program. It runs the U.S. and Foreign Commercial Service (US\&FCS), which provides export education and organizes a range of activities including individual company visits to foreign countries, trade missions, reverse-trade missions, and trade fairs. The US\&FCS has offices throughout the world.

ITA provides access to its programs, products, or services to all interested parties. Geographic coverage is generally worldwide on an industry sector basis. Assistance efforts focus primarily on the private sector in countries where significant market potential exists for U.S. exports.

International Trade Administration

U.S. Department of Commerce

14th \& Constitution Avenue, NW

Washington, DC 20230

Phone: 800-872-8723

Fax: 202-482-4473

Internet: http://www.ita.doc.gov

Department of State. U.S. State Department commercial and economic staffs provide briefings and advice on international business culture and practices to U.S. firms traveling overseas. The department's foreign service officers are responsible for commercial work in embassies and consulates not covered by the US\&FCS, and work closely with their US\&FCS colleagues worldwide.

Office of the Coordinator for Business Affairs U.S. Department of State

Washington, DC 20520-6810

Phone: 202-647-1625

Fax: 202-647-3953

Internet: http://www.state.gov
Export-Import Bank of the United States (ExIm Bank). The Ex-Im Bank provides a range of export credits for U.S. goods and services, underwriting credit risks not accepted by the private sector. The Ex-Im Bank offers four major export finance support programs: loans, guarantees, working capital guarantees, and export credit insurance. It also has an office that specializes in project finance transactions.

To be eligible for Ex-Im Bank funding, the goods or services to be exported must have at least 50 percent U.S. content and must address the following criteria: use of a U.S. export, existence of foreign government-subsidized competition, economic viability, reasonable repayment assurance, and effect on the U.S. economy.

Any entity engaged in the export or in export financing of U.S. products is eligible to participate in Ex-Im Bank's insurance programs. For coverage to be available, at least 50 percent of the value of a product must consist of labor and materials of U.S. origin. The exporter may become a policyholer directly or work through a policy held by a commercial bank.

Export-Import Bank

Business Development Group

811 Vermont Avenue, NW

Washington, DC 20571

Phone: 202-565-3946

Fax: 202-565-3380

Internet: http://www.exim.gov

\section{Overseas Private Investment Corporation}

(OPIC). OPIC assists U.S. private investment to qualified overseas ventures through direct loans and loan guarantees. It insures investment projects against a broad range of political risks and provides a range of other investor services. OPIC insurance and financing are currently available in 140 countries around the world. Funds may be used for power and industrial applications.

To obtain OPIC assistance, proposed projects must demonstrate social and economic benefits to the host country as well as consistency with the economic goals of the United States. Each project must also be shown to be commercially 
and financially sound. Project developers need to submit a business plan to OPIC that includes detailed information on the project, background and financial status of the developer, proposed project financing, and impacts on the local economy and social structure. OPIC may request additional information or utilize independent analysts, if necessary. Projects must also show demonstrated competence of the proposed management, and those proposing the project must undertake significant financial risk. Proposed projects must be approved by the host country.

Overseas Private Investment Corporation 1100 New York Avenue, NW

Washington, DC 20527

Phone: 202-336-8799

Fax: 202-408-9859

Internet: http://www.opic.gov

Trade and Development Agency (TDA). The TDA awards funds to host nations for major capital infrastructure development project feasibility studies performed by U.S. consulting companies. TDA grants support studies to establish the economic, financial, and technical feasibility of proposed projects. Other support includes technical assistance grants, orientation visits (reverse-trade missions), training grants, and other planning services.

To receive TDA funding, a host country must choose a U.S. company to perform the project feasibility study. TDA does not fund studies for projects unless U.S. goods, services, and technology are considered internationally competitive. It relies on consultations with technical advisors, other agencies, and private sector groups to make this judgment. TDA-funded studies focus on infrastructure development in such sectors as energy, wastewater treatment, transportation, and telecommunications.

U.S. Trade and Development Agency

Arlington, VA 22209

Phone: 703-875-4357

Fax: 703-875-4009

Internet: http://www.tda.gov

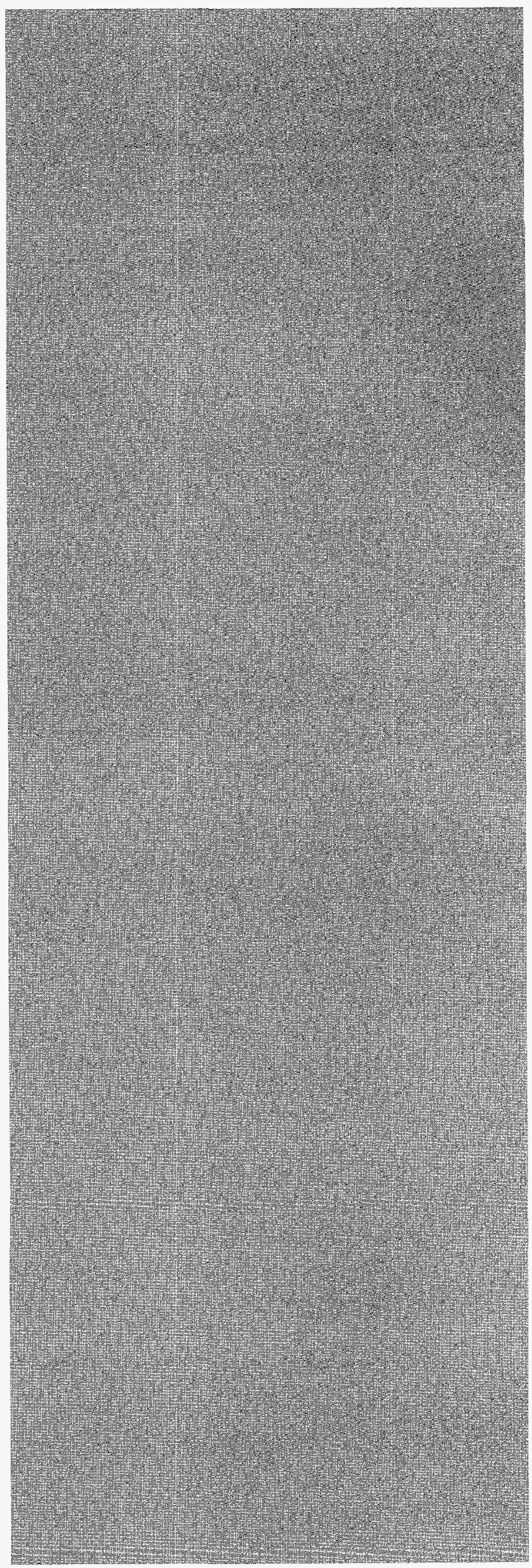



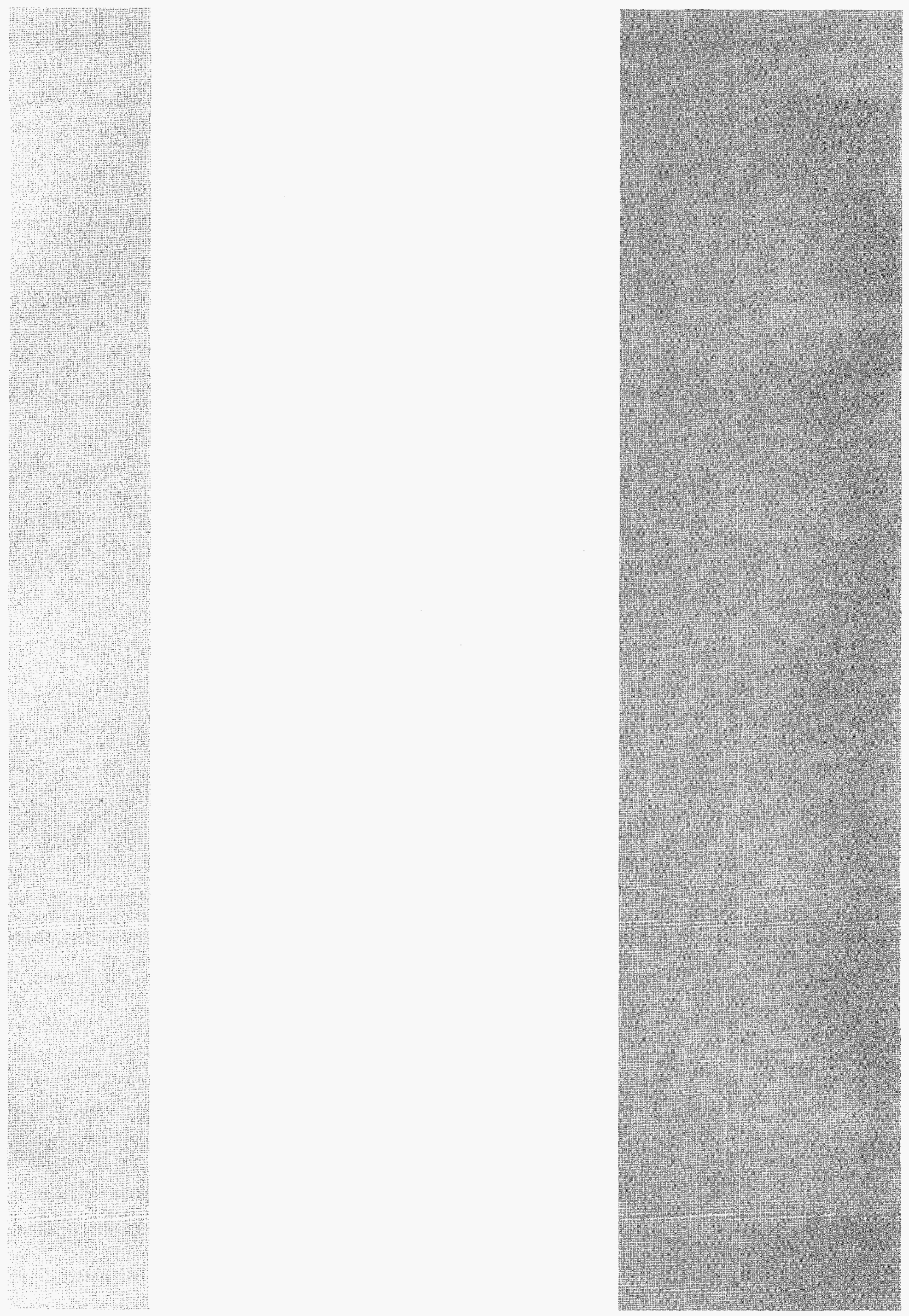


\section{Clean Coal Technology INFORMATION REQUEST \\ FAXBACK Form}

Name:

Title:

Organization:

Address:

Country:

Phone: Fax: E-mail:

Please send me information on (check all that apply):

Type of Technology Coal Cleaning Low-Rank Upgrading Combustion Technology Post-Combustion Technology Other
Type of Application

__ New Power Plant

Retrofit

Repowering Industrial Application Other
Type of Information Needed Technology Description Technical Performance

__ Vendors

_ Cost Other

Comments:

Fax to:

Attention: Barbara N. McKee U.S. Department of Energy Office of Fossil Energy Office of Coal \& Power Import and Export 1000 Independence Avenue, SW

Washington, DC 20585

USA

Fax Number: 1-301-903-1591

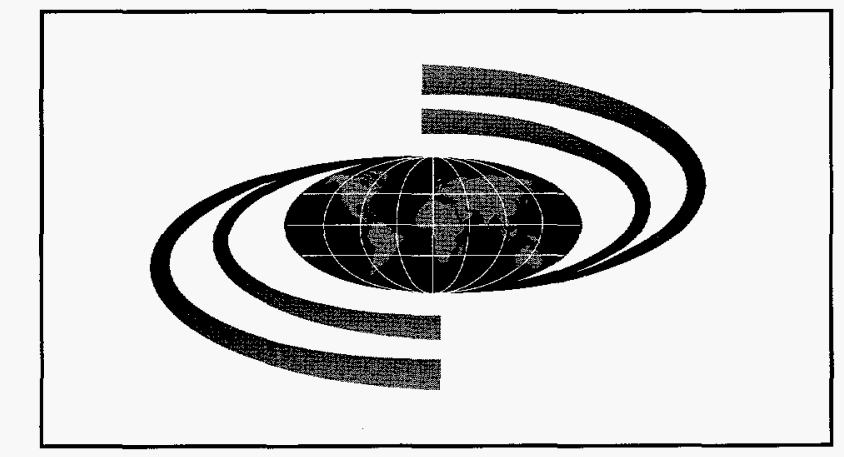



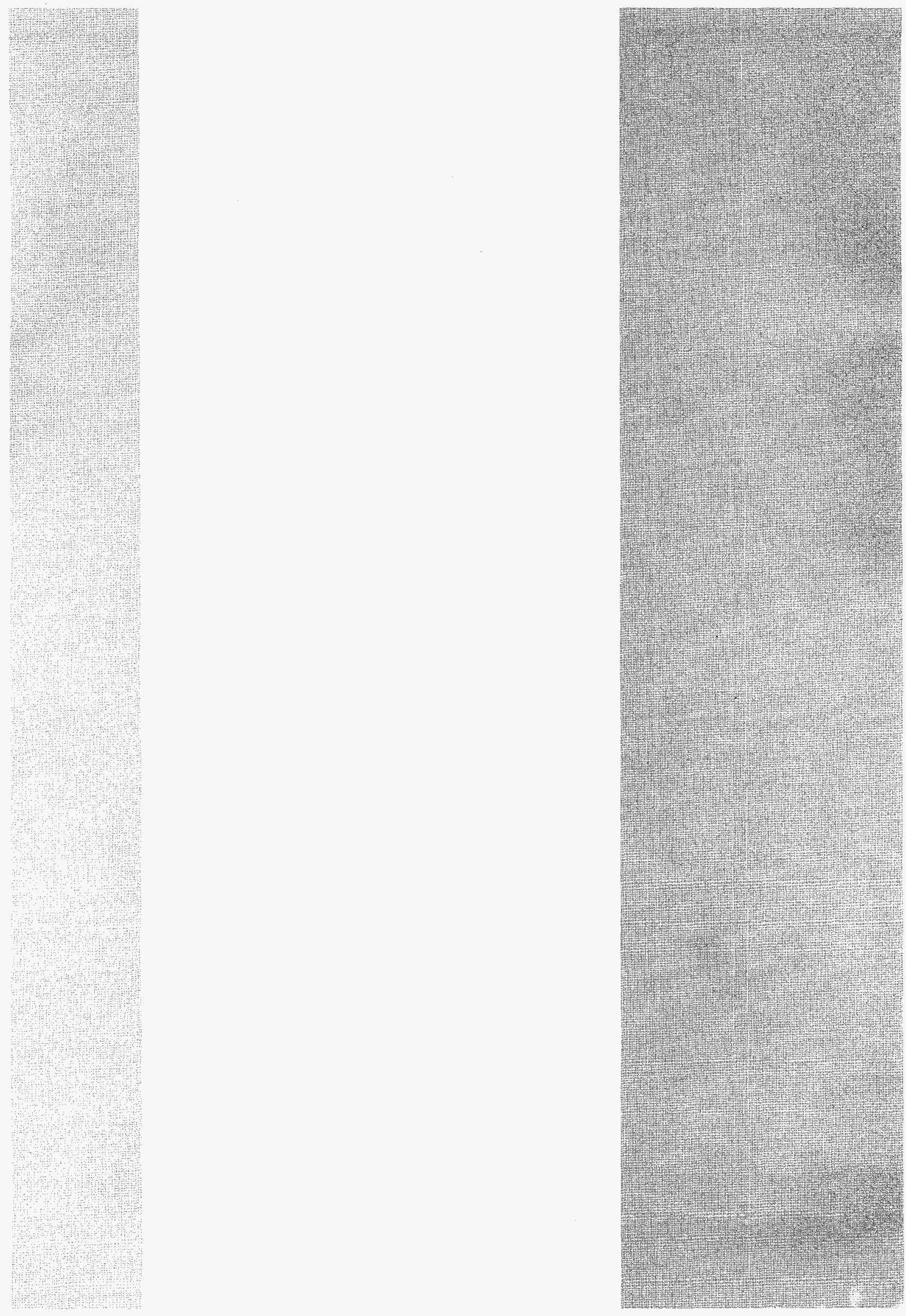


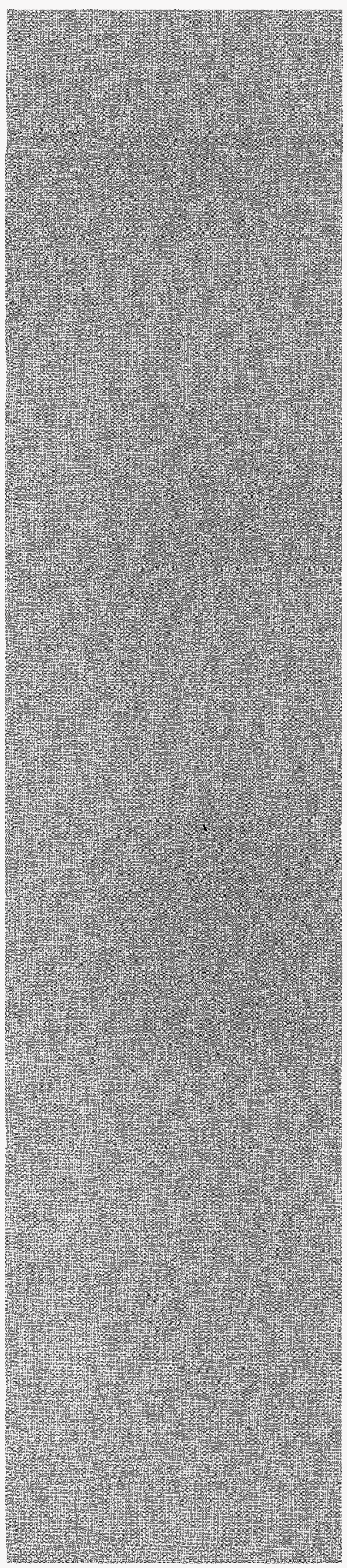

\section{APPENDIX \\ Today's Clean Coal TeChNologies}

Clean coal technologies fall into four categories: pre-combustion, combustion, post-combustion, and conversion. The majority of these technologies are already producing clean coal on a commercial basis, and more are expected to come into even wider use in the years ahead. Some clean coal technologies are nearing or are now in the final stages of research prior to commercialization. This appendix describes commercial technologies already in widespread use. 

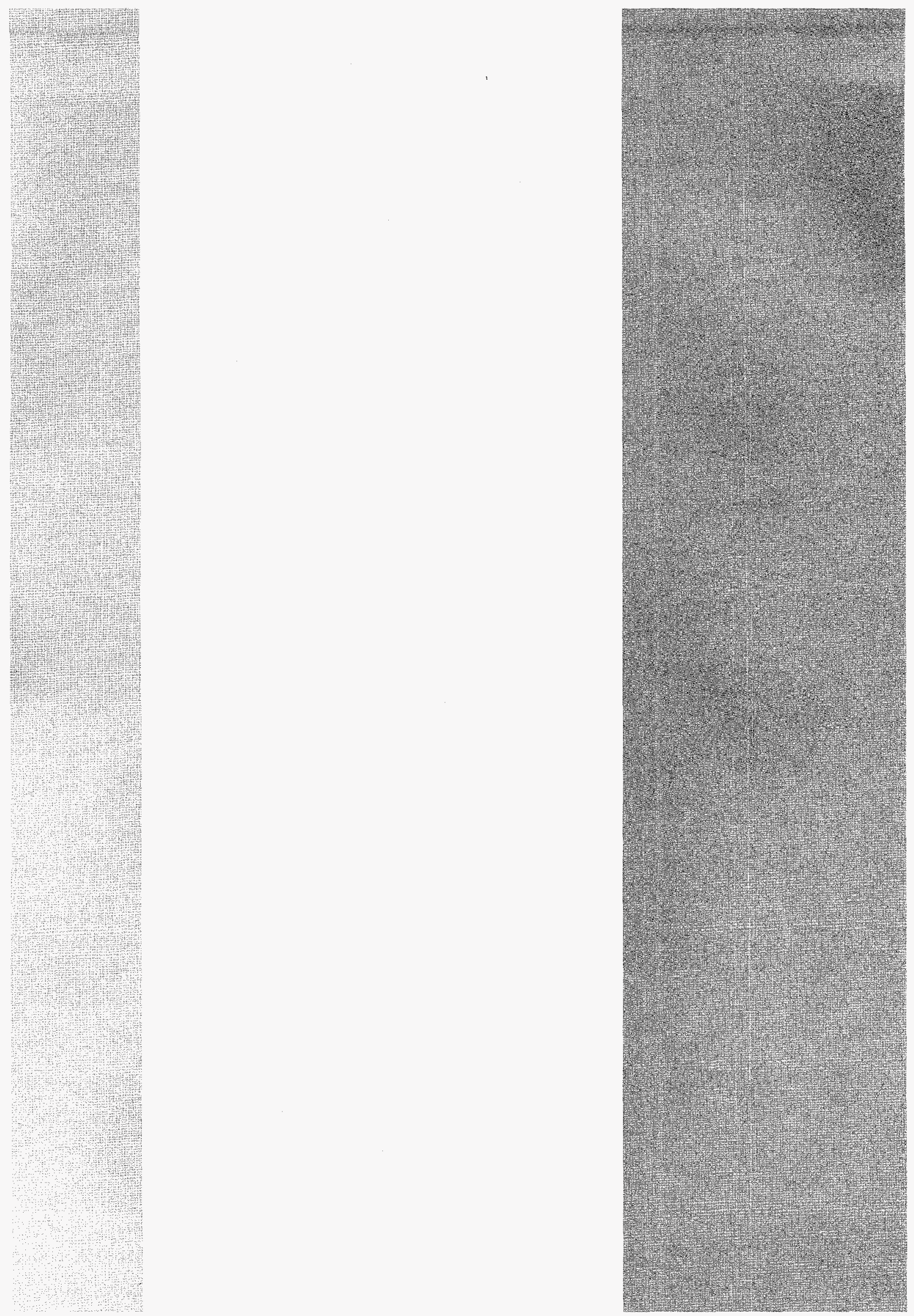


\section{Precombustion Coal Preparation}

$\mathrm{R}$ aw coal contains sulfur and ash-forming matter that contribute to emissions and reduce coal's heating value. Years ago, when coal was mined by pick and shovel, quality was maintained by handloading only visibly clean coal. The productivity of this method was low. As advances in technology retired the pickax and hand loading gave way to mechanical loading, productivity improved, but impurities in the mined coal increased.

The coal preparation process changes or controls the properties of run-of-mine coal and improves coal performance in end-use applications such as combustion in a pulverized coal boiler. Coal preparation usually refers to coal cleaning, or "beneficiation," to improve the quality of bituminous coal. Techniques are also used to improve subbituminous and lignite coals, particularly to lower their moisture content. Depending on the type and level of cleaning, coal quality can be improved in several ways:

- Reduced sulfur content

- Reduced ash content

- Higher heat content

- Improved size distribution

- Lower moisture

- Less variation in coal quality

Benefits to the coal user include reduced sulfur dioxide and particulate emissions, lower operating and maintenance costs, and greater plant availability. In addition, capital costs of utilization equipment can sometimes be reduced through use of higher-quality coal. Coal cleaning, which often takes place at or near the mine prior to shipment, removes ash and sulfur from the coal so that less material needs to be shipped. This indirectly reduces transportation costs per unit of heat input to a power plant. As developing countries have coals with high ash content, coal cleaning is an effective means for reducing particulate emissions in these countries.

\section{Physical Cleaning}

Physical cleaning removes ash-forming minerals and other impurities, such as sulfur, to improve combustion properties of the coal and reduce pollutant emissions. Other advantages include lower transportation costs and reduced combustion equipment maintenance.

Physical cleaning removes matter that is physically distinct from the coal, such as small dirt particles, rocks, and pyritic sulfur. It separates undesirable matter from the coal by relying on differences in densities, particle sizes, and surface properties. The raw coal is usually crushed to create particles within a certain size range. Appropriately sized sieves separate most of the ash-forming minerals, and water sprayed over the coal particles then loosens much of the remaining mineral matter.

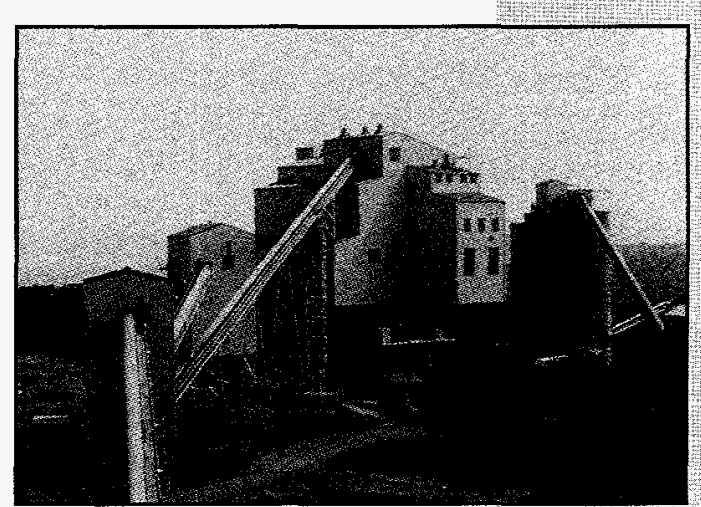

The 500-ton/hour Custom Coals International facility removes up to 90 percent of the pyritic sulfur in the coal. 
Deeper cleaning methods immerse the coal in a controlled-density solution. Coal is less dense than its resident mineral matter, and in solutions with specific gravities between 1.3 and 1.8, buoyancy differences separate them. Coal and mineral matter also have different surface properties, and advanced commercial cleaning systems take advantage of these differences. In these systems, fine air bubbles are passed through a solution containing the uncleaned coal. Since air bubbles attach to coal more easily than to mineral matter, the coal particles become even more buoyant facilitating the separation process.

Significant quantities of pyritic sulfur - an ironsulfur compound physically attached to coal are typically removed with the mineral matter. While physical coal cleaning does not remove organic sulfur, which is chemically linked to the coal, removal of pyritic sulfur substantially reduces the amount of sulfur released during combustion. Physical cleaning commercially in use today removes 30 to 50 percent of pyritic sulfur (10 to 30 percent of total sulfur) in coal, and approximately 60 percent of ash-forming minerals. Unfortunately, physical cleaning does not remove nitrogen from coal, and therefore has little impact on nitrogen oxide emissions.

Coal cleaning processes can augment existing pollution control equipment and decrease environmental impacts of coal combustion at less expense and downtime than retrofitting plants.

\section{Low-RANK Upgrading}

The main limitations on the use of subbituminous coal are the relatively low energy and high moisture contnts of the coal compared to higherrank bituminous coals. Subbituminous coals are used where their low delivered costs and sulfur content are offset by their low energy content. Considerable research has been performed in the United States in recent years to develop methods to clean subbituminous coal by drying, increasing heating content, and pelletizing. Such methods are just now reaching commercial status and may be beneficial to countries having abundant reserves of highmoisture, low-rank coal.
Lignites, due to their very low heat content and tendency to degrade or even spontaneously combust over time, are often burned in power plants sited at the mine. Lignites are also very high in moisture content and may be thermally dried prior to utilization.

Many countries have large reserves of the lowrank lignite, and subbituminous coals. The high moisture content of these coals adds weight and also absorbs heat during combustion, lowering the useful energy available in a given amount of coal. Low-rank coals can be upgraded primarily through cleaning and drying - to increase the value of the coal and lower the shipping costs.

Most commercial coal cleaning methods for low-rank coal are similar to precombustion cleaning methods in that they rely on physical differences between the coal and mineral matter. Coal crushing, particle separation using sieves, and coal washing are performed to separate the ash-forming minerals.

Coal drying relies on evaporative techniques, supplying heated air through coal in a fixed or fluidized bed or a rotary kiln system. Coal drying improves the value of many low-rank coals, which can have moisture levels of up to 40 percent. The moisture in many low-rank coals resides in pores and crevices, where weak attractive forces exist. Although the moisture can be removed through evaporation, the weak attractive forces remain. In the presence of ambient water, the coal has a tendency to reabsorb moisture, often releasing heat and creating a danger of self-combustion. These technical problems have limited the widespread adoption of coal drying. 


\section{Bituminous Coal Preparation}

Preparation processes applied to bituminous coals can be classified by the level of treatment given the coal. There are four basic levels of cleaning, with higher levels removing more impurities but requiring more equipment and therefore costing more. Currently, only coal cleaning methods that separate impurities from coal based on physical differences between the coal and those impurities are in commercial use.

\section{Level 1 - Crushing and Screening.}

This process consists of breaking up the coal to a suitable size for power plant use, then sorting the pieces by size. Screening may also be used to separate coal pieces by size for further preparation. No cleaning - removal of ash or sulfur - takes place. While exact streams vary among preparation plants, three broad size categories are generally used:

- Coarse - pieces that can pass through screens with openings larger than about one centimeter

- Mid-sizes - pieces from about 0.8 millimeter to one centimeter

- Fines - particles smaller than 0.8 millimeter.

\section{Level 2 - Coarse Coal Cleaning.}

Crushing of the coal frees some of the ash materials and sulfur. Gravity separation methods are used to remove these impurities, but only for coarse streams. Smaller particles are produced uncleaned to the extent that they can be recovered.

\section{Level 3 - Coarse and Mid-Range Cleaning.} The portion of the impurities freed from the coal usually increases as the particle size decreases. Both coarse and mid-range particles are cleaned, and the mid-size particles are dried.

\section{Level 4 - Deep Cleaning.}

Particles in all three size categories are cleaned and midsize and fine particles are dried.

The effectiveness of coal cleaning, the design of the cleaning process, and cleaning are functions of many characteristics of the coal. Extensive testing of coal characteristics is performed before a preparation plant is designed. Some of the more important coal characteristics affecting coal cleaning measured in these tests are: sulfur content and type, ash types and characteristics, moisture content, grindability, and the specific gravities of the coal and impurities. Pre-combustion coal cleaning reduces ash content by 75 to 90 percent, while advanced physical coal cleaning processes achieve between 10 and 65 percent sulfur removal depending on the nature of the sulfur in the coal and the exact preparation method.

Ash is the residue from non-combustible mineral matter that remains after burning. Two types of ash-forming mineral material are contained in coals: inherent mineral matter and extraneous mineral matter. Inherent mineral matter comes from the chemical elements that existed in the plants from which the coal formed. Extraneous mineral matter is foreign material from sources other than the plants that formed the coal, usually consisting of shale, sandstone, clay or other mineral matter from the roof and floor of the mine. 


\section{Economics and Performance}

The feasibility of coal cleaning is very specific to the requirements of the end user and the characteristics of the coal. Many developing and transitional countries use coal for power generation and for other industrial, commercial, and domestic applications. For example, coal is widely used in industrial boilers in China and India, and for domestic heating in Poland. Increased coal prices associated with cleaning the coal must be justified by the benefits to the user. The economic effect is best evaluated by an end-use economic analysis of the total impact on the cost of electricity or other applications of burning cleaned versus raw coal. Where there are multiple sources or qualities of coal, whether cleaned or raw, the relative economics of all sources is compared at the busbar.

The major cost of coal cleaning includes the capital and operating cost of the preparation plant. In addition, some combustible material may be lost with the impurities or in the cleaning process. These losses must also be taken into account.

The improvement in coal quality at each level on which the end user benefits are based is highly dependent on the specific characteristics of the coal. Up to 30 percent of the sulfur can be removed in some coals; in others, sulfur removal may be as low as 10 percent. Up to 60 percent of the ash may be removed. Important tradeoffs are made between coal quality (as measured by sulfur, ash and heat content) and thermal yield (the fraction of the energy content of the original coal contained in the cleaned product). As quality improves, yield declines as more materials are lost in the preparation process. Typical thermal yields of the cleaned coal range from 80 to 98 percent. Careful analysis is required to determine the optimum cleaning method for a specific requirement. For this reason, coal preparation plants are usually custom designed.

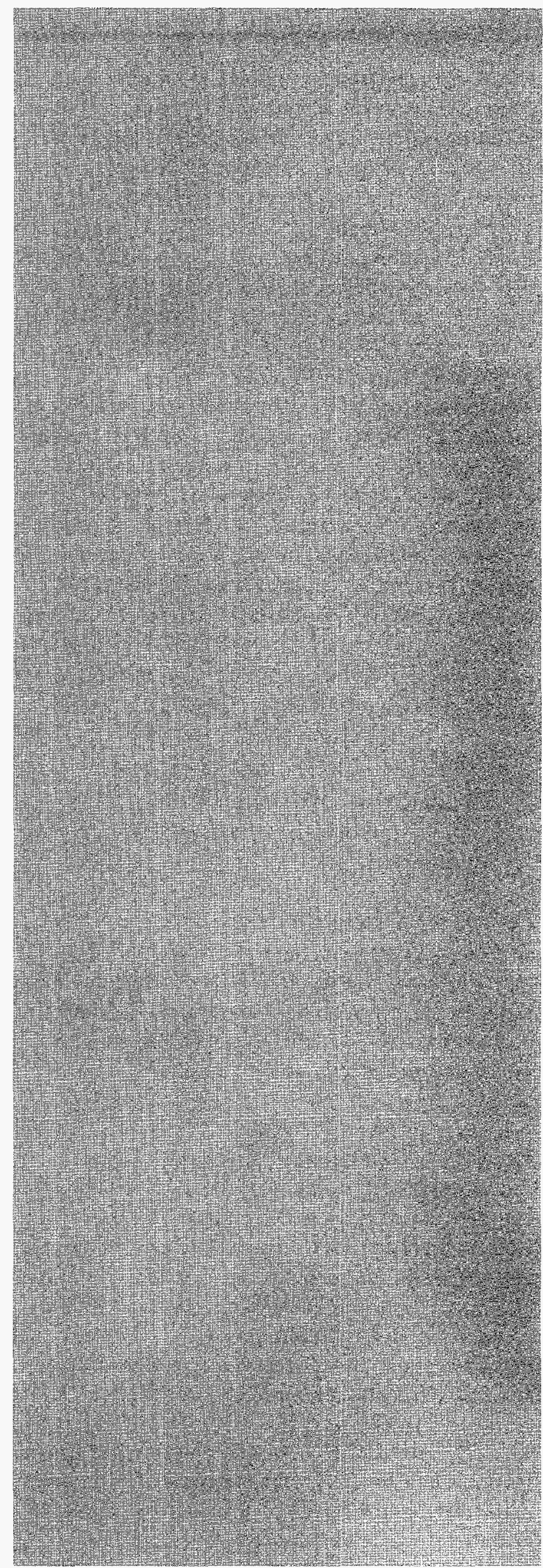




\section{Combustion Technologies}

Coal can be cleaned as it burns. In response to the demand for efficient and environmentally benign coal utilization, combustion processes have improved significantly over the last two decades.

In most large-scale, conventional coal combustion plants, raw coal is pulverized into particles small enough to form a combustible mixture and then injected with hot air into burners along the lower portion of a hollow rectangular box called a steam boiler. Coal burns in a long, luminous flame in the furnace cavity at temperatures of at least $1,480^{\circ} \mathrm{C}$. The heat is transferred to waterfilled tubes typically welded into the sides of the boiler. The boiling water in the tubes creates steam that either spins a turbine generator to produce electricity or provides some other service.

Several clean coal technologies that combine high efficiencies and low pollutant emissions have been developed and are now commercially available. These technologies include fluidized bed combustion and nitrogen oxide control.

\section{Fluidized Bed Combustion}

Fluidized bed combustion provides a high-sulfur capture rate while improving the thermal efficiency of the plant. Rather than blowing a mixture of tiny coal particles into the combustor, crushed coal mixed with limestone is suspended on jets of air. This "bed" of coal and limestone actually floats inside the boiler, tumbling in a manner that resembles a boiling liquid, hence the name "fluidized." As the coal burns, sulfur is released. The limestone acts like a chemical sponge capturing the sulfur before it can escape the boiler. More than 90 percent of the sulfur released from coal can be captured in this manner.

The sulfur-laden limestone forms a dry waste-product. Some of the solid waste is removed with the bed ash through the bottom of the boiler. Smaller ash particles, or "fly ash," are carried out of the boiler and captured with dust collectors.

Because the tumbling motion of the coal enhances the burning process, combustion temperatures in a fluidized bed combustor can be held to around $760^{\circ} \mathrm{C}$ to

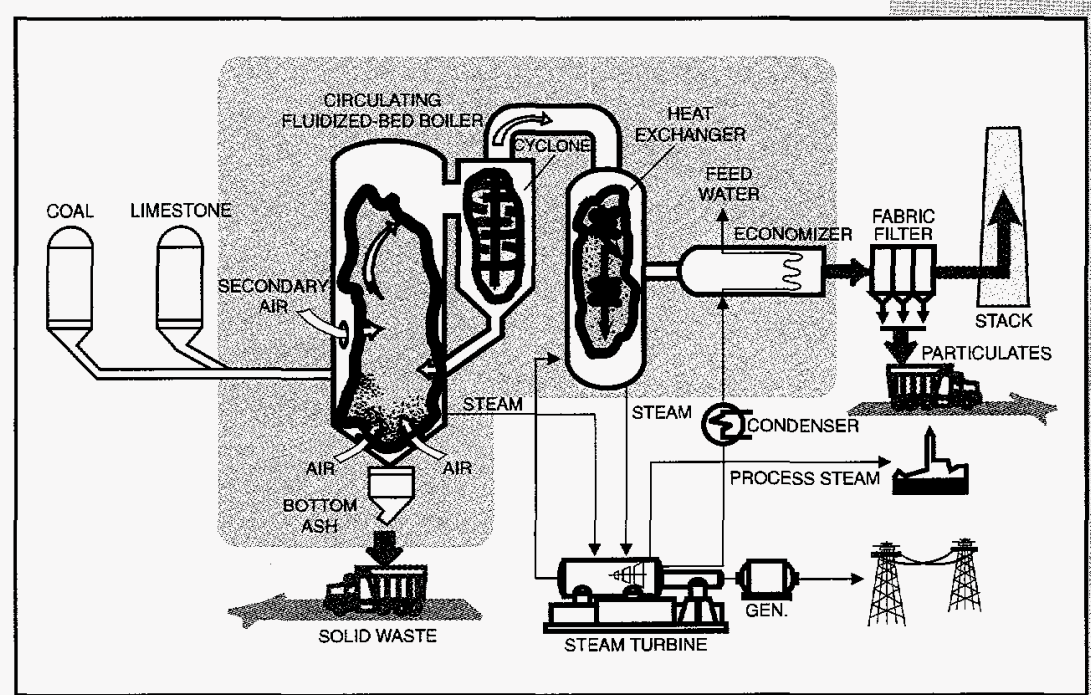

Principal elements of a fluidized bed combustion process are shown above. $870^{\circ} \mathrm{C}$ - almost half the temperature of a conventional boiler. This temperature range is below the threshold where nitrogen pollutants form, thus allowing both sulfur dioxide and nitrogen oxide standards to be met without additional pollution control equipment. 
There are two principal types of fluidized bed combustion: atmospheric fluidized bed combustion (AFBC), which operates at normal atmospheric pressures; and pressurized fluidized bed combustion (PFBC), which operates at pressures 6 to 16 times higher than normal atmospheric pressure. PFBC applications tend to achieve higher efficiencies than comparable AFBC systems. Because of the increased energy in the high-pressure gases exiting the boiler, PFBC can drive both a gas and steam turbine, in an arrangement known as a combined cycle system. These systems can boost power generating efficiencies to well above 40 percent.

AFBC technology is a wellestablished option for large, industrial sized boilers, at scales roughly equivalent to 10 to 25 megawatts. In Europe and the United States, approximately 300 AFBC units supply heat to industrial processes, municipalities, oil producers (for thermal recovery processes), and farms (for hay drying). AFBC technology has also moved into the much larger 75- to 350-megawatt scales necessary for utility plants.

\section{Nitrogen Oxime Controls}

Another set of combustion control technologies is designed to lower nitrogen oxide emissions in pulverized coal applications. In conventional pulverized-coal furnaces, coal crushed to the consistency of flour is mixed with combustion air, injected into the furnace, and burned at temperatures approaching $1,500^{\circ} \mathrm{C}$. Unfortunately, the chemical reactions that form $\mathrm{NO}_{\mathrm{x}}$ proceed readily at these high temperatures when there is sufficient oxygen. Technologies such as staged combustion, overfire air (OFA) burners, and low- $\mathrm{NO}_{\mathrm{x}}$ burners - minimize $\mathrm{NO}_{\mathrm{x}}$ formation by regulating flame temperature and the fuel/air mixture.
Staged combustion separates the combustion process into different regions of the furnace. The pulverized coal is injected and burned in a region of insufficient combustion air. As the partially burned fuel moves up the furnace, air is added incrementally and the combustion reaction proceeds. This method minimizes conditions promoting high levels of $\mathrm{NO}_{x}$ formation.

OFA uses air ports in the furnace wall above the top row of burners to create a fuel-rich, low-NO $\mathrm{NO}_{\mathrm{x}}$ combustion zone. While this technique requires fewer hardware changes than low-NO $\mathrm{N}_{\mathrm{x}}$ burners, it only reduces $\mathrm{NO}_{\mathrm{x}}$ formation by 15 to 30 percent.

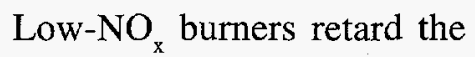
conversion of nitrogen to $\mathrm{NO}_{x}$ by delaying the mixing of fuel and air in the burner zone. Keeping the primary combustion zone oxygen deficient, low- $\mathrm{NO}_{x}$ burners can cut $\mathrm{NO}_{\mathrm{x}}$ formation by nearly 50 percent.

Another variation of $\mathrm{NO}_{\mathrm{x}}$ control is natural gas reburning. In this process, a small amount of natural gas - 10 to 20 percent of the total fuel input - is injected above the normal combustion zone to form an oxygen-deficient zone. Other reburning concepts use coal instead of natural gas.

\section{Supercritical Steam Generators}

Metallurgical constraints limit the temperature of steam system operations to below the $538^{\circ} \mathrm{C}$ to $590^{\circ} \mathrm{C}$ range; however, constraints on pressure are less restrictive. Pulverized coal plants are of two different variations: those that operate at pressures between 10,340 and 16,550 kilopascals, and those that operate at pressures up to 24,820 kilopascals. Steam systems that operate at pressures above 22,120 kilopascals - the critical pressure of water - are known as "supercritical steam generators." Because supercritical steam has more energy, the thermal efficiencies of these systems can be 4 percent higher than those of comparable subcritical systems. 


\section{Post-Combustion Cleaning}

$\mathrm{U}$ ntil the emergence of clean coal technologies, post-combustion cleaning was the principal method of meeting air quality standards. Post-combustion cleaning techniques available today remove as much as 99.9 percent of particulates, 95 percent of sulfur pollutants from flue gases, and up to 80 percent of the nitrogen pollutants.

\section{Particulate Control}

The principal methods of collecting particulates in exhaust gas streams are through the use of baghouses and electrostatic precipitators (ESPs). Baghouses use fabric filters to capture particulates while allowing the gases to pass through. As the particulates collect, pressure drops across the filters. Then either the support structure holding the filters is violently vibrated or a jet of air is shot back across the filter to dislodge the dust, which falls to the bottom of the baghouse for disposal.

ESPs use an electromagnetic field to capture solid particles. Relying on the ability to transfer a charge to particles in exhaust gases, ESPs use the attractive force of an oppositely charged surface to pull the particles out of the gas. An advantage of ESPs is their comparatively low back-pressure. The effectiveness of ESPs is highly dependent on the properties of the flue gas, which in turn depends on the characteristics of the coal, combustion processes, and other pollution control equipment.

\section{Sulfur Dioxide Control}

Flue gas desulfurization (FGD) processes use sorbents to remove sulfur from the exhaust gas stream. In older FGD systems, the flue gas is humidified then passed through a bed of limestone. As the sorbent becomes saturated with sulfur, it is removed from the system and disposed. Newer FGD systems use dry processes and sorbent regeneration, which lessen the amount of sorbent required and lower disposal costs.

Some FGD processes use an additive to boost sulfur capture. For example, adding certain chemicals to the scrubbing solution may permit as much as 97 percent sulfur dioxide $\left(\mathrm{SO}_{2}\right)$ removal. Other concepts rely on a series of chemical reactions to eliminate both $\mathrm{SO}_{2}$ and $\mathrm{NO}_{\mathrm{x}}$. One device uses copper oxide to change $\mathrm{SO}_{2}{ }_{2}$ into copper sulfate which, when combined with ammonia, converts $\mathrm{NO}_{x}$ into nitrogen.

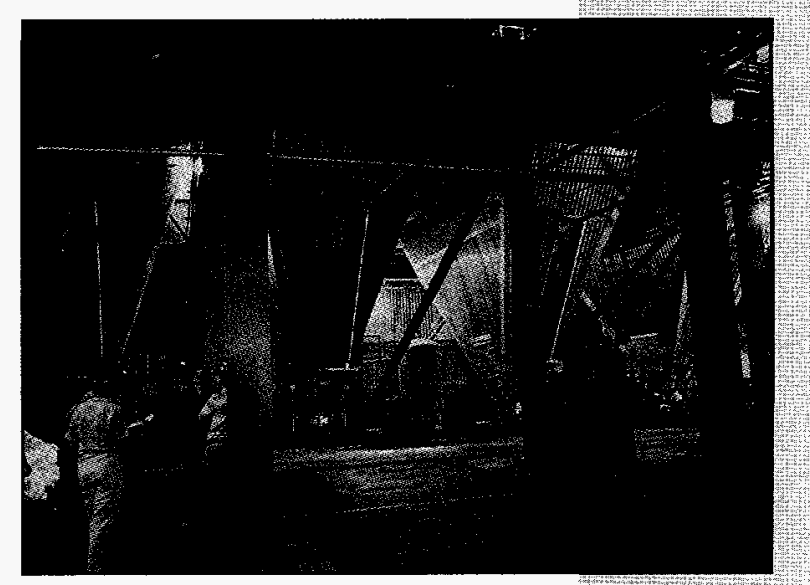

Public Service Company of Colorado's Arapahoe Station baghouses capture particulate matter. which is removed at the bottom of the conical

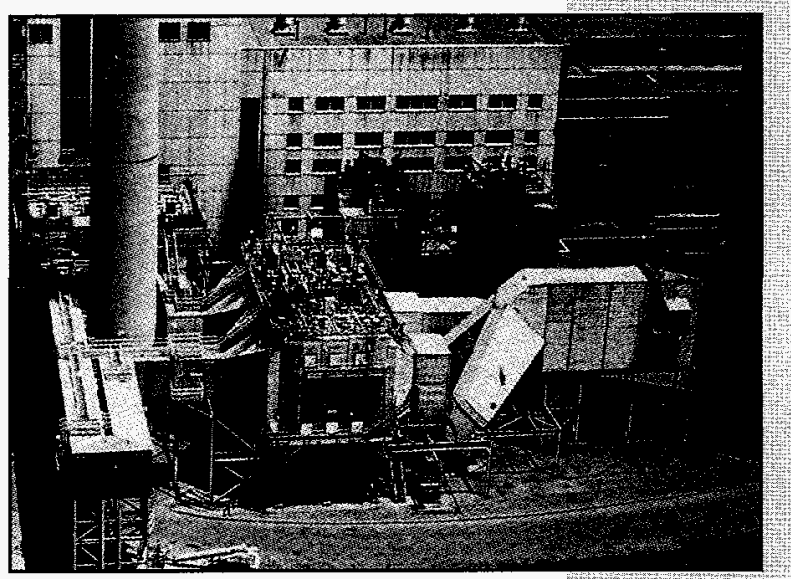

Bechtel Corporation's electrostatic precipitator, shown atop Pennsylvania Electric Company's Seward Plant collector house, uses oppositely charged collecting plates energized by the electrical gear to capture particulate matter. 
FGD processes can be grouped according to where in the physical layout of the power plant each performs its sulfur-removing functions. One type of FGD is in-duct sorbent injection, which sprays sulfur absorbers - such as lime - into the center of the exhaust duct. By carefully controlling the humidity of the flue gas and spray pattern of the sorbent, 50 to 70 percent of $\mathrm{SO}_{2}$ can be removed. The reaction produces dry particles that can be collected downstream. Because FGD uses a plant's existing ductwork, extensive new construction is not needed. In-duct injection is also attractive for retrofitting smaller and older plants, which may not have enough space to install new scrubber systems.

FGD facilities can also be located outside the main power plant to allow the incorporation of additional system capabilities, including:

- Regenerating the sulfur-absorbing chemical, making the system more economical;

- Removing both $\mathrm{SO}_{2}$ and $\mathrm{NO}_{\mathrm{x}}$;

- Producing an environmentally benign, dry waste product;

- Streamlining operations by reducing or eliminating the need for reheating or backup modules.

\section{Nitrogen Oxide Control}

Recent innovations in treating flue gases make it possible to reduce $\mathrm{NO}_{\mathrm{x}}$ in flue gases as they leave the coal boiler, instead of requiring modifications to the combustor. Post-combustion $\mathrm{NO}_{\mathrm{x}}$ control technologies include selective catalytic reduction (SCR) and selective noncatalytic reduction (SNCR). In these systems, ammonia or urea reacts with nitrogen oxide and nitrogen dioxide to form molecular nitrogen. Since SCR systems use a catalyst to promote this reaction, their conversion rate is typically higher. The feasibility of both technologies depends on the $\mathrm{NO}_{x}$ content of the flue gas and targeted emissions levels. SCR is a commercial technology widely used in many countries, including the United States, Japan, and Germany. In SCR systems, ammonia is mixed with flue gas and passed through a reaction chamber separate from the scrubber vessel. In the presence of a catalyst, $\mathrm{NO}_{\mathrm{x}}$ is converted by the ammonia to molecular nitrogen and water. SCR systems are projected to reduce nitrogen oxides emissions by 50 to 80 percent.

In SNCR systems, a urea solution is sprayed into the boiler's convective zones at carefully controlled temperatures, promoting the reaction of $\mathrm{NO}_{x}$ and urea into harmless nitrogen and water. This process can reduce nitrogen oxide emissions by up to 30 percent and can be combined with other low- $\mathrm{NO}_{x}$ combustion techniques.

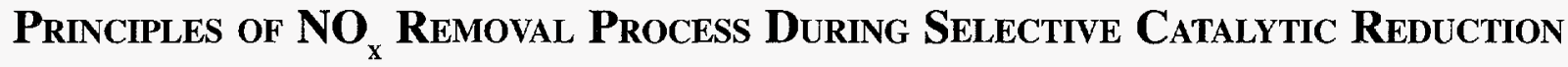

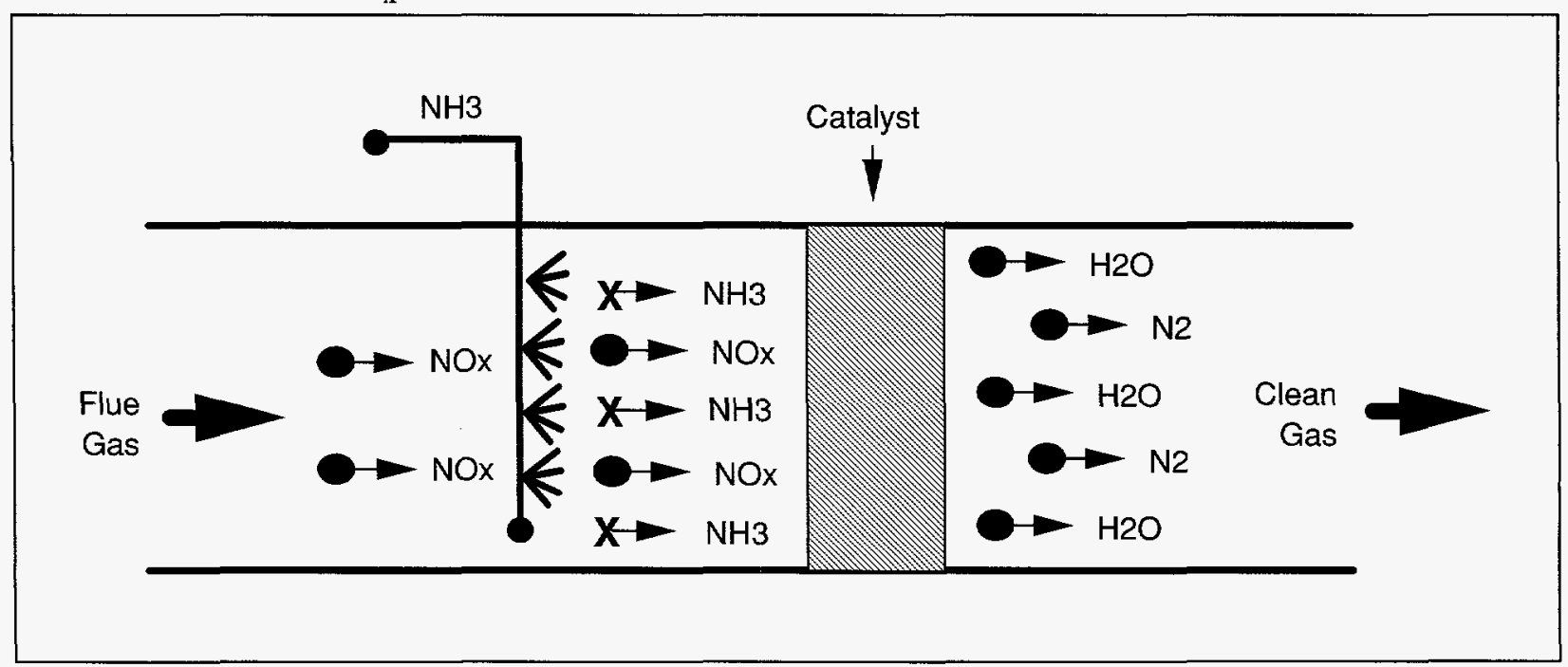




\section{Conversion}

Conversion technologies change coal into a different fuel form. The most widely used conversion process gasifies coal by exposing it to high-pressure, high-temperature air, or oxygen. In the gasification process, coal is broken apart by a reaction with steam and oxygen (or air). A mixture of carbon monoxide and hydrogen is produced, and the sulfur in coal is released in the form of hydrogen sulfide rather than sulfur dioxide. Several commercial processes are capable of removing hydrogen sulfide, and more than 99 percent of the sulfur can be removed from the gas, making it as clean as natural gas. The cleaned fuel gas is subsequently burned in a combustion turbine while by-products, such as hydrogen sulfide, are typically isolated and sold as separate products.

The conversion process has four steps:

1. Coal is broken into gaseous molecules by bringing it into contact with high-temperature steam and oxygen (or air).

2. The gases are purified, to avoid pollution and protect turbine components from chipping or corroding.

3. The clean gases are burned and the hot exhaust is routed through a gas turbine to generate electricity.

4. Residual heat in the exhaust is used to boil water for a conventional steam turbine generator, producing more electricity.

Sulfur, nitrogen compounds, and particulates are removed both before the fuel is burned in the combustion turbine and before combustion air is

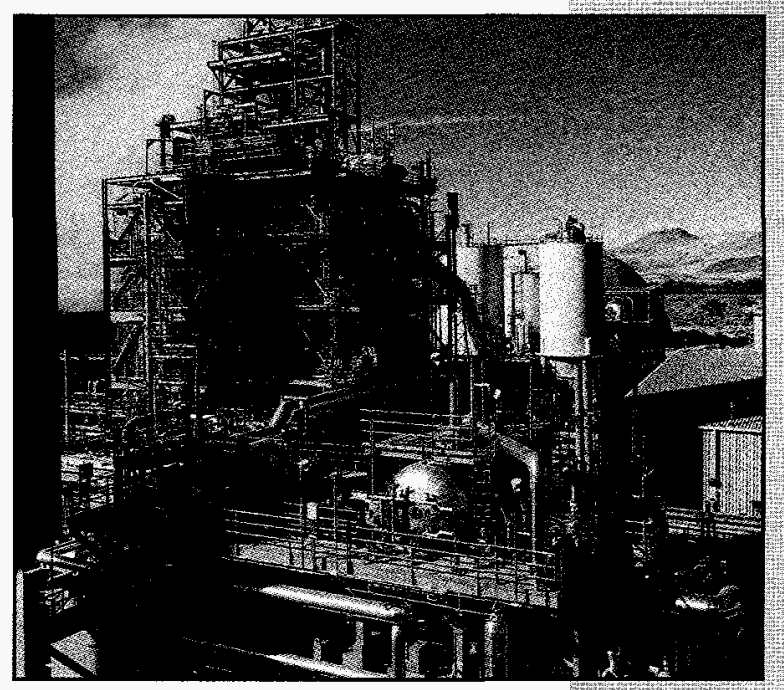

The Piñon Pine IGCC Power Project demenstrates a gasification process that offers 43 percent thermal efficiency and does not require an oxygen separator. added. For this reason, there is a much lower volume of gas to be treated than in a post-combustion scrubber.

High levels of nitrogen removal are also possible in the conversion process. Some nitrogen is converted to ammonia, which can be almost completely removed by straightforward chemical processes. $\mathrm{NO}_{\mathrm{x}}$ formed from the combustion air can be held to well within allowable levels by staging combustion within the turbine or by adding moisture to keep flame temperature down.

Gasification also offers fuel flexibility. Gasifiers can accommodate a comparatively wide range of coals, enabling plants to operate using different sources of coal. Although some conversion processes convert coal into liquid for use as a chemical additive, coal-derived liquids are more applicable to the chemical processing industry. 


\section{INTEGRATED GASIFICATION Combined Cycle}

Coal gasification used with a combined cycle power system offers high thermal efficiencies as well as improved pollutant control. Known as integrated gasification combined cycle (IGCC), the process converts coal into a fuel gas that can be cleaned and then burned in a combustion turbine. IGCC systems are among the cleanest of clean coal technologies. Since exhaust gases from the combustion turbine are sufficiently hot, they can also generate steam to power a steam turbine. The thermal efficiencies of combined cycle plants are usually above 45 percent.

IGCC technology provides many advantages including excellent pollutant capture, high thermal efficiencies, and fuel flexibility. Fuel gas is cleaned prior to combustion, which avoids the cost, space, and solid-waste problems of flue gas treatment. Some pollutants, such as hydrogen sulfide, can be sold to chemical plants, providing an additional revenue stream.

The gasification process also allows a relatively broad range of coals to provide the fuel gas. This fuel flexibility offers the ability to use different sources of coal as prices and availabilities change. In addition, the combustion turbines used with IGCC systems are typically designed for low-grade fuel gases, allowing the use of alternative gas sources.

Since IGCC technology uses both gas and steam turbines, it offers advantages of modular plant construction. For example, the combustion turbine module of a plant can be operated while the heat recovery steam generator is constructed. This modular approach allows the plant to generate revenue during construction, lowering financing costs. It also allows the plant to expand to meet increased demand.

IGCC has undergone rapid development since the 1980 s and is now in the early stages of commercial availability. Several IGCC commercial plants now operate in the United States and Europe, such as the Tampa Electric IGCC Project, Piñon Pine IGCC Power Project, and the Wabash River Coal Gasification Repowering Project.

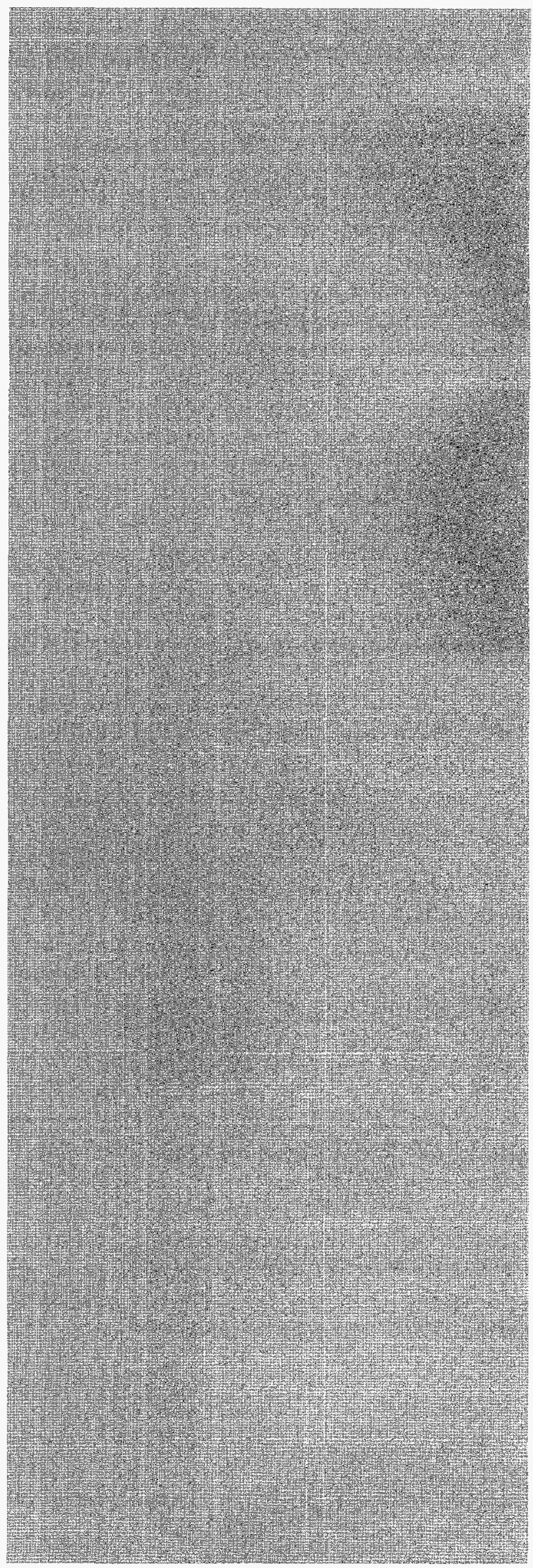




\section{GLOSSARY}

Acid rain: Also called acid precipitation or acid deposition; precipitation containing nitric and sulfuric acids formed by $\mathrm{NO}_{x}$ and $\mathrm{SO}_{x}$ released into the atmosphere when fossil fuels are burned.

Anthracite: Coal with a heating value of $28,000-32,600 \mathrm{~kJ}$ per $\mathrm{kg}$ and carbon content of $86 \%$ to $97 \%$; see Coal rank.

Atmospheric fluidized bed combustor: A device in which fluidized bed combustion occurs at atmospheric pressure. This is the most popular application of fluidized bed combustion.

Baghouse: A pollution control device which uses fabric filters to capture particulate in a flue gas exhaust stream.

Bituminous: Coal with a heating value of 24,400-32,600 kJ per $\mathrm{kg}$ and carbon content of $45 \%$ to $86 \%$; see Coal rank.

Boiler: Device that absorbs heat, usually from a combustion process, to boil water and create pressurized steam. Tubes that run into a furnace or combustion chamber provide heat exchange surfaces to add energy to the water.

Burner: Device that injects a fuel and air mixture into a combustion chamber. The reaction between the fuel and air releases heat.

Briquettes: Blocks of coal made by heating and compressing coal particles, usually in the presence of binders. Briquettes tend to have higher heat content and lower smoke and pollution characteristics than raw coal.

Calorie: The amount of heat needed to raise the temperature of 1 gram of water 1 degree Celsius at $15^{\circ} \mathrm{C}$.

Clean coal technologies: Advanced innovative systems designed to produce power from coal more efficiently and economically than conventional coal burning processes while reducing environmental impacts.
Coal beneficiation: Coal treatment, cleansing, or preparation to remove mineral or ash material.

Coal gasification: The conversion of coal into a gaseous fuel.

Coal rank: An indication of the degree to which organic matter has been converted to coal. Rank is based on the fixed carbon, volatile matter, and heating value of a coal.

Coke: A hard, dry substance of mostly carbon made from bituminous coal baked at very high temperatures in the absence of air, by a process called carbonization. Used chiefly as a fuel and reducing agent in smelting iron ore in a blast furnace, coke has a heating value of about $27,000 \mathrm{~kJ}$ per metric ton.

Combined cycle: A technology for generating electricity in which the heat output from combustion turbines is used to generate steam for further electricity production. Electricity is generated by both the combustion and steam turbines.

Combustion (or gas) turbine: A device in which hot combustion gases expand to drive a generator and compressor.

Compressor: A pump or other type of machine using a turbine to compress a gas.

Coprocessing: The mixing and subsequent processing of coal and heavy, residual oil through a refining-like process to create a lighter, higher quality liquid.

Electrostatic precipitator: A device that removes ash particles from combustion gases using an electrical charge.

Fines: Coal with a maximum particle size usually less than $1.5 \mathrm{~mm}$ and rarely above 3.2 $\mathrm{mm}$.

Flue gas desulfurization: Process that uses a sorbent to capture sulfur in the exhaust stream of a combustion chamber. 
Fluidized bed combustor (FBC): A device in which crushed coal mixed with limestone is suspended on jets of air while it burns. The powdery limestone absorbs sulfur as it is released. Low burning temperatures keep $\mathrm{NO}_{x}$ from forming. Two principal types are atmospheric FBC (AFBC) and pressurized FBC (PFBC) which refer to the pressure in the combustor.

Fossil fuel: Any fuel of an organic nature (carbon containing), such as coal, crude oil, natural gas, or synthetic fuels.

Gas reburning A technique in which coal is fired in a main heat-release zone in the lower part of a boiler and natural gas is burned in a cooler, oxygen-deficient zone in the upper part of the boiler to control the formation of $\mathrm{NO}_{\mathrm{x}}$

Generator: A machine that converts mechanical energy into electrical energy.

Greenhouse effect: The phenomenon that occurs when certain gases accumulate in the atmosphere allowing the sun's energy to penetrate to the earth but trapping heat radiated from the earth's surface.

Identified resources: Coal identified from geologic evidence and engineering measurements, estimated at 1.04 trillion metric tons worldwide.

In-duct sorbent injection: A technique in which limestone is sprayed into ductwork between the boiler and smokestack to absorb sulfur pollutants.

\section{Integrated gasification combined cycle} (IGCC): A power generating system in which coal is converted to a fuel gas, which is burned to drive a gas turbine generator and a steam turbine generator.

Lignite: Coal with a heating value of 11,600 $16,300 \mathrm{~kJ}$ per $\mathrm{kg}$, carbon content of $25 \%$ to $35 \%$, and high moisture content; see Coal rank.
Metallurgical ("met") coal: Grades of coal with compositions suitable for making coke for reducing iron ore as a step in steel manufacturing; has particularly good agglomerating capabilities, high Btu and low ash content.

Methane: The chief constituent of natural gas; produced by decaying plant material or by coal gasification processes.

Mine-mouth power plant: A steam-electric power plant built close to a coal mine.

Natural gas: A naturally occurring mixture of hydrocarbons (principally methane) and small quantities of other gases found in porous geological formations, often in association with petroleum.

Pressurized fluidized bed combustor: A device in which fluidized bed combustion occurs under pressures 6 to 16 times atmospheric pressure. The energy of the exhaust gases is capable of driving a separate turbine, which improves overall process efficiency.

Proved reserves: The estimated resources that geological and engineering data demonstrate with reasonable certainty to be recoverable in future years from known reservoirs or deposits under existing economic and operating conditions.

Pulverized coal plants: The most common type of coal plant. Coal is crushed to the consistency of a powder, mixed with combustion air, and sprayed into a furnace.

Recoverable reserves: Also called proved reserves; coal reserves that are likely to be mined and used.

Repowering: Replacing all or part of the outmoded power generating equipment in a power plant with modern systems.

Retrofitting: Installing modern pollution control devices on older facilities without making major changes in plant design. 
Run-of-mine coal: Coal as it comes directly from the mine, not treated or sized by a preparation plant.

Scrubber: Any of several forms of post-combustion devices that cause sulfur in gaseous emissions to react with other chemical to form either a waste product or, in newer technologies, a reusable by-product.

Selective catalytic reduction (SCR): $\quad \mathrm{A} \mathrm{NO}_{x}$ removal process in which ammonia is first mixed with flue gas and passed through a reaction chamber separate from the scrubber vessel; then in the presence of a catalyst, $\mathrm{NO}_{\mathrm{x}}$ and ammonia are converted to molecular nitrogen and water.

Selective non-catalytic reduction (SNCR): A $\mathrm{NO}_{\mathrm{x}}$ removal process in which ammonia or urea is injected into a flue gas to convert the $\mathrm{NO}_{\mathrm{x}}$ into molecular nitrogen and water.

Sorbent: An alkaline substance that combines with sulfurous gases to create a solid substance that can be removed from coal flue gases.

Steam coal: Coal used by a power plant or industrial steam boiler to produce electricity; generally lower in Btu content than "met" coal.

Subbituminous: Coal with a heating value of $19,300-26,750 \mathrm{~kJ}$ per $\mathrm{kg}$ and carbon content of $35 \%$ to $45 \%$; see Coal rank.

Sulfur: An element present in varying quantities in coal; contributes to environmental degradation when coal is burned. The sulfur content in coal is low if $1 \%$ or less, medium if between $1 \%$ and $3 \%$, and high if over $3 \%$.

Supercritical steam generator: A steam generator that operates at pressures above the supercritical pressure of water, 22.1 megapascals. These plants are generally more efficient than subcritical plants.

Turbine: A device with rotating vanes for generating rotary mechanical power from the kinetic energy in a stream of fluid or gas.

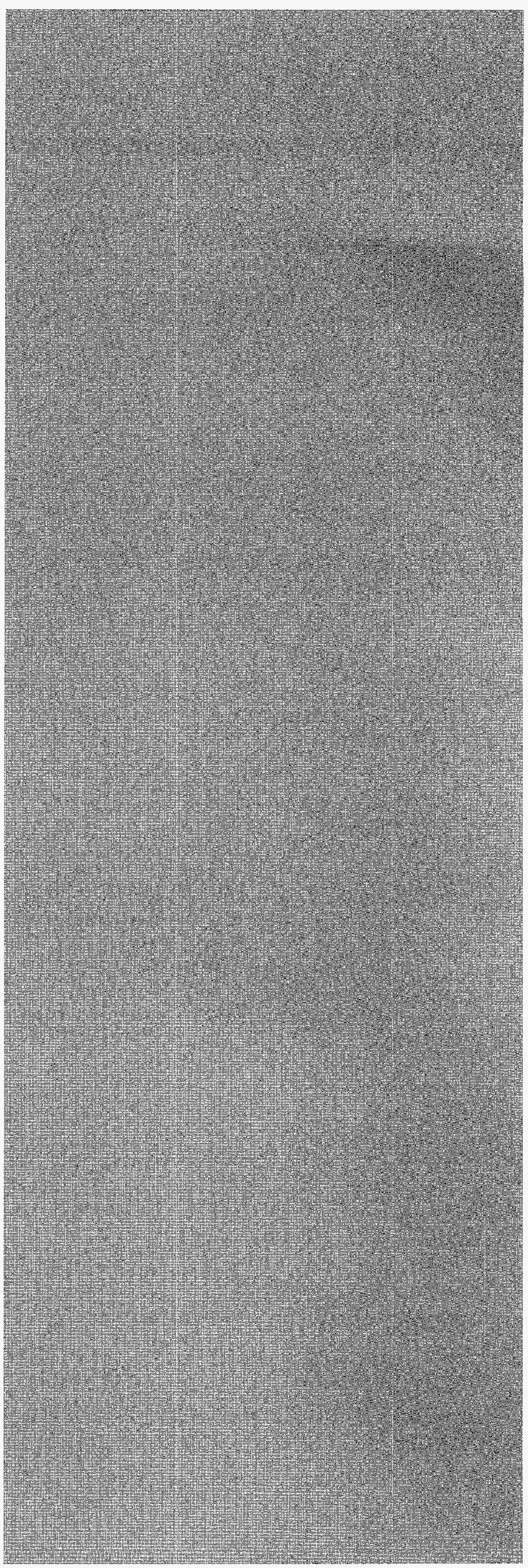



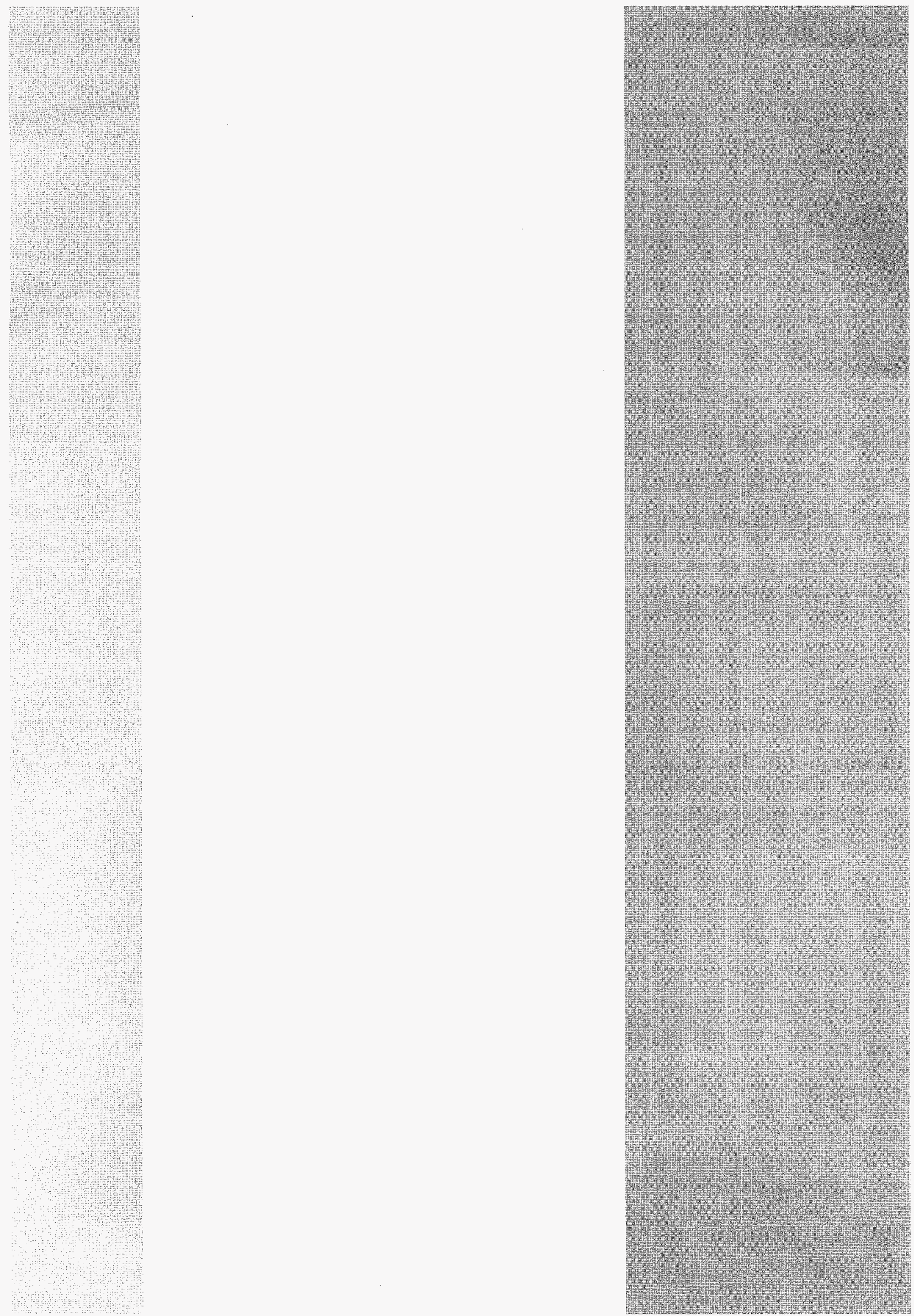